\title{
Explaining Dysfunctional Effects of Lexicographical Communication*
}

\author{
Herman L. Beyer, Department of Language and Literature Studies, \\ University of Namibia, Windhoek, Namibia (hbeyer@unam.na)
}

\begin{abstract}
During a keynote address at an international conference of AFRILEX articles from a bilingual dictionary with Afrikaans as one of the treated languages was presented. One of the articles was that of the lemma vuvuzela, which contained the example sentence Vuvuzelas maak ' $n$ groot lawaai by sokkerwedstryde [ \pm Vuvuzelas make a lot of noise at soccer matches]. A member of the audience criticised this example for apparently not reflecting the notion of festivity and celebration, with which the vuvuzela is also associated; instead, it seemed that the example focused only on a negative feature of the vuvuzela. From the ensuing discussion it became clear that there seemed to be no theoretical framework against which the criticism could be validated and productively dealt with, even though the lexicographer ultimately offered to review the example.

This article introduces elements of the theory of lexicographical communication and applies them to scaffold such a framework. It is argued that indicators in dictionary articles can be regarded as lexicographic utterances that carry various types of lexicographic messages. These can be systematically and formally analysed to identify functional, non-functional and dysfunctional effects of lexicographical communication. Problems with lexicographical communication can then be diagnosed and addressed. This potential is illustrated by treating the above-mentioned occurrence as a case study. In conclusion, the value of the relevant elements of the theory for the evaluation of dictionaries is briefly outlined.
\end{abstract}

Keywords: APPEAL, DICTIONARY, DYSFUNCTIONAL EFFECT, EXPRESSIVE, FUNCTION, FUNCTIONAL EFFECT, INFORMATION, LEXICOGRAPHER, LEXICOGRAPHIC MESSAGE, LEXICOGRAPHIC UTTERANCE, LEXICOGRAPHICAL COMMUNICATION, LEXICOGRAPHY, NON-FUNCTIONAL EFFECT, REFERENTIAL, RELATIONAL, TARGET USER

Opsomming: Die verklaring van disfunksionele effekte van leksikografiese kommunikasie. Gedurende ' $n$ hoofreferaat by ' $n$ internasionale konferensie van AFRILEX is artikels van ' $n$ tweetalige woordeboek met Afrikaans as een van die behandelde tale aangebied. Een van die artikels was dié van die lemma vuvuzela, wat die voorbeeldsin Vuvuzelas maak ' $n$ groot lawaai by sokkerwedstryde bevat het. ' $\mathrm{n}$ Lid van die gehoor het hierdie voorbeeld gekritiseer omdat volgens hom dit nie die idee van feestelikheid weerspieël waarmee die vuvuzela ook geassosieer word nie; dit het naamlik gelyk of die voorbeeldsin op slegs 'n negatiewe aspek van die vuvuzela fokus. Uit die voortspruitende bespreking het dit geblyk dat daar nie 'n teoretiese raamwerk

* An earlier version of this article was presented as a paper at the Nineteenth Annual International Conference of the African Association for Lexicography (AFRILEX), which was hosted by the Research Unit for Language and Literature in the SA Context, North-West University, Potchefstroom Campus, Potchefstroom, South Africa, 1-3 July 2014. 
bestaan waarvolgens die kritiek bekragtig en produktief hanteer kon word nie, afgesien daarvan dat die leksikograaf aangebied het om die voorbeeldsin te hersien.

Hierdie artikel stel elemente van die teorie van leksikografiese kommunikasie bekend en pas hulle toe om so 'n raamwerk te skep. Daar word aangevoer dat aanduiders in woordeboekartikels beskou kan word as leksikografiese uitings wat verskillende tipes leksikografiese boodskappe dra. Hulle kan sistematies en formeel analiseer word om funksionele, niefunksionele en disfunksionele effekte van leksikografiese kommunikasie te identifiseer. Probleme met leksikografiese kommunikasie kan dan gediagnoseer en opgelos word. Hierdie potensiaal word geillustreer deur die toepassing van die teorie op die bogenoemde voorval as 'n gevallestudie. Ter afsluiting word die relevante elemente van die teorie se waarde in die evaluering van woordeboeke kortliks uiteengesit.

Sleutelwoorde: APPÈL, DISFUNKSIONELE EFFEK, EKSPRESSIEF, FUNKSIE, FUNKSIONELE EFFEK, INLIGTING, LEKSIKOGRAAF, LEKSIKOGRAFIE, LEKSIKOGRAFIESE BOODSKAP, LEKSIKOGRAFIESE KOMMUNIKASIE, LEKSIKOGRAFIESE UITING, NIEFUNKSIONELE EFFEK, REFERENSIEEL, RELASIONEEL, TEIKENGEBRUIKER, WOORDEBOEK

\section{Introduction}

This article was prompted by an occurrence during question time after one of the keynote addresses at the annual international conference of the African Association for Lexicography (AFRILEX) held in Port Elizabeth, South Africa, from 2 to 5 July 2013. The keynote address in question dealt with a bilingual dictionary that is being compiled with Afrikaans as one of the treated languages. One of the aspects touched upon during the address was example phrases and sentences. In this regard the article of the lemma vuvuzela, inter alia, was presented. This article contained the following Afrikaans example sentence: Vuvuzelas maak 'n groot lawaai by sokkerwedstryde [ \pm Vuvuzelas make a lot of noise at soccer matches]. In a comment during question and discussion time one delegate expressed disappointment at the fact that he could not observe the notion of festivity and celebration, with which the vuvuzela is also associated, in the example. It seemed regrettable to him that the vuvuzela is associated only with excessive noise in the dictionary article. In response to this comment, the keynote speaker and some members of the audience argued that the example sentence was included due to the relatively high co-occurrence of the type vuvuzela with the type noise in the relevant corpus. However, this line of defence did not seem to satisfy the objection. Ultimately, the keynote speaker offered that the dictionary article in question could eventually be revisited and revised to address the criticism.

What became clear during the discussion, however, was that there seemed to be no metalexicographical framework against which this type of criticism could be validated and dealt with productively. The aim of this article is to address this research problem by tentatively offering such a framework. This proposed solution falls within the parameters of a theory of lexicographical communication. 
Firstly, the elements of the theory of lexicographical communication that scaffold the proposed framework will be developed, after which the focus will fall on the research problem itself. In conclusion the value of the framework for the formative and summative evaluation of dictionaries will be outlined in the form of a set of general guiding questions.

The theory that is introduced in this article allows for formal representations of propositions and qualities, as will become apparent. However, most of the formal representations are accompanied by natural language equivalents and therefore the article can be read without having to interpret each formal representation.

It should be stated at this point that the purpose of this article and the theory presented in it is not to choose any side in the apparent disagreement between the lexicographer and the delegate, nor is it to resolve any issue surrounding the vuvuzela. The research problem is the absence of a scientific framework for discussion. The purpose of the study is to provide a scientific framework which, it is hoped, could facilitate fruitful discussion in addressing issues like the one raised above.

\section{The theory of lexicographical communication}

The theory of lexicographical communication (= TLC) can be regarded as an ongoing study to determine to what extent a specific communicative perspective might facilitate new and ideally innovative theorising in lexicography. A systematic exposition of the foundations of this approach has not been published as yet, but is being prepared: Beyer (in preparation). However, some preliminary elements have been tentatively and informally applied in Beyer (2009, 2010, 2011 and 2013).

With a "communicative perspective" is meant an approach originating from communication theory. A basic definition of the core concept communication is therefore in order for the purposes of this article (translated and slightly adapted from Van Cuilenburg et al. 1992: 10):

(1) Communication is a process during which a sender conveys information via a medium to a receiver with the goal of achieving a specific effect with the receiver.

The concept lexicographical communication refers to a specialised type of communication limited to specific types of information (i.e. about lexical items) and a specific type of medium (i.e. the dictionary) for specific types of effects. In lexicographical communication the lexicographer usually plays the role of the sender (in so far as the concept lexicographer can be defined - cf. Gouws 2012) and the target user plays the role of the receiver. The concept information will be dealt with in section 3 below.

The TLC is being developed from the lexicographical communication 
model first proposed by Beyer (2006) in an effort to present a framework for the systematic description of user-friendliness in dictionaries. Subsequently, Yong and Peng (2007) independently proposed a communicative approach to bilingual lexicography. ${ }^{1}$ Ptaszyñski (2009: 212), in reviewing the work, refers to it interchangeably as "the communicative theory of lexicography" and "the communication theory of lexicography". Although Yong and Peng's work is based on an alternative communication model and consequently differs almost fundamentally from the current TLC, it served as an inspiration to further explore the potential of a communication model for theory development in lexicography. ${ }^{2}$

Since Beyer (2006) the model has evolved somewhat but has not changed fundamentally. It can now be presented in figure 1:

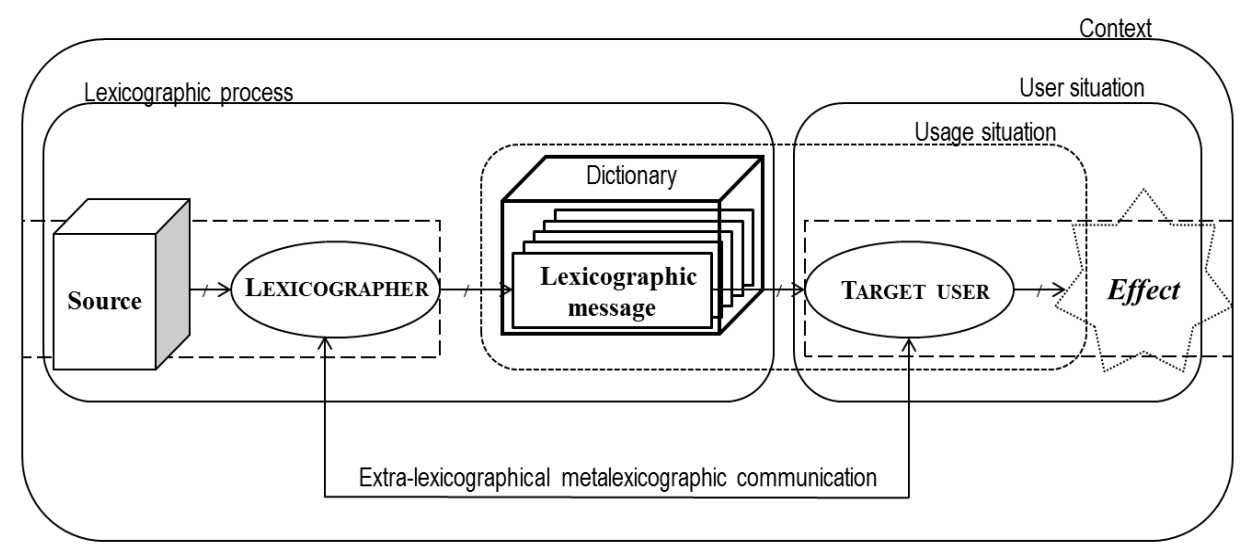

Figure 1: A lexicographical communication model

In this model a number of components of the process of lexicographical communication can be distinguished and described, as is done preliminarily in Beyer (2006). Two of these components are the primary components or immediate constituents of this process, namely the lexicographic process on the one hand and the dictionary consultation process (i.e. the user situation in fig. 1) on the other. They overlap to both enclose the lexicographic message and its container, the dictionary as the medium of lexicographical communication. The other components, e.g. the source, the lexicographer, the target user and the user situation, are related to either of the primary components. Even though the components can be individually identified and described, the model illustrates their mutual dependency and necessity: lexicographical communication cannot take place if one of them is missing. The only component that overarches the primary components is the context component, which represents variables that are not part of the communication process per se, but determine 
the values of at least a subset of the variables in all other components while the reverse is not applicable to the same extent. This component will be elaborated on in section 6.3.

In reading the lexicographical communication model above, the TLC can be summarised as describing a sub-process, the lexicographic process, during which the lexicographer sources, selects and encodes lexicographical information in a lexicographic text segment, followed by a second sub-process, the dictionary consultation process, during which the dictionary user decodes and interprets the lexicographic message in the usage situation. This is followed by the effect of the communication process, when the user applies the meaning of the lexicographic message to the user situation. Both sub-processes and their effect occur in a particular context (cf. 6.3). At the centre are the lexicographic message and its container, the dictionary.

Cruse (2011: 5) presents the following stages in a typical act of linguistic communication, each of which he subsequently discusses in more detail:

(2) a. The speaker normally has a purpose in communicating.

b. The speaker constructs a message to be communicated.

c. The speaker constructs an utterance with which to convey the message.

d. The speaker transforms the utterance into a physical signal.

e. The speaker transmits the signal.

$\mathrm{f}$. The addressee receives the signal.

g. The addressee decodes the signal to recover the utterance.

$h$. The addressee reconstructs the message from the utterance.

i. The addressee infers the purpose of the communication.

The strong identity between the process of lexicographical communication and linguistic communication is obvious and not surprising, since language is a code system used for communication. Contemporary lexicographical theories emphasise the view that lexicography is not a branch of linguistics or applied linguistics (cf. e.g. Tarp 2008), although this view is not universally accepted (cf. e.g. Atkins and Rundell 2008, Fontenelle 2011). Whichever opinion applies, the value of linguistics in practical and theoretical lexicography should be acknowledged, simply because the code system generally employed for lexicographical communication is language, as shown above. It could be argued that linguistic theory might perhaps not always be best suited for explaining why and what types of information should be encoded in a given type of dictionary and what structures should frame the lexicographic utterances, but it surely has the potential to contribute to explaining how lexicographic messages are encoded in lexicographic utterances, how the utterances are decoded and interpreted, and how the target user applies the derived information. (Cf. also Bogaards 2010.)

In a review of Tarp (2008) which concludes that the function theory fails as a theory, Piotrowski (2009: 485) states in closing: 
[A] new theory of lexicography would be one that would take seriously what we know now about pragmatics and discourse, text structure, [sic] and would account for the contribution of particular textual elements to the dynamic meaning of a text...

Taking Piotrowski's cue and considering the views of other critics of the function theory (cf. Bogaards 2010, De Schryver 2012, Rundell 2012), the potential of the discipline of pragmatics in the development of the TLC is currently being investigated. Of particular interest seems to be speech act theory, which was first proposed by Austin (1962) and further developed by Searle (1969, etc.), and which is in fact considered as a branch of the theory of communication (Kempson 1977, Bierwisch 1980). The basic elements of speech act theory are applied later in this article (cf. 4.2.4). Another theory in pragmatics that seems promising for application to lexicographical communication and accommodation in the TLC is the theory of conversational implicature (Grice 1975, etc.). Levinson (1983: 101-102) summarises Grice's co-operative principle and maxims with regard to the efficient and effective use of language (i.e. communication), which would clearly also resonate strongly with the lexicographer, as follows:

(3) a. The co-operative principle

Make your contribution such as is required, at the stage at which it occurs, by the accepted purpose or direction of the talk exchange in which you are engaged.

b. The maxim of Quality

Try to make your contribution one that is true, specifically:

(i) do not say what you believe to be false;

(ii) do not say that for which you lack adequate evidence.

c. The maxim of Quantity

(i) Make your contribution as informative as is required for the current purposes of the exchange.

(ii) Do not make your contribution more informative than is required.

d. The maxim of Relevance

Make your contributions relevant.

e. The maxim of Manner

Be perspicuous, and specifically:

(i) avoid obscurity;

(ii) avoid ambiguity;

(iii) be brief;

(iv) be orderly.

Furthermore, the TLC emphasises the textual nature of lexicographical communication. As such, it explores, in addition to existing lexicographical and communication theory, disciplines like discourse analysis, text linguistics and document design in attempting to describe lexicographical communication. 
The focus now turns to lexicographic messages in approaching the research problem.

\section{Lexicographic messages}

As stated above, communication is a process of conveying information. Following Cleary (2003: 5) and Steinberg (2007: 45-46), the concept of information in human communication can be described as follows:

(4) Information is the factual knowledge, ideas, thoughts and feelings that can be conveyed by means of communication.

In order for the information to be conveyed, it first has to be constructed into a message, which can then be encoded into an utterance (following Cruse's stages of linguistic communication). From this a definition for the concept message can be derived logically:

(5) A message is a unit of information that can be encoded in an utterance.

An utterance, in turn, is a discrete unit of communication that consists of a sign or an ordered string of signs forming symbols (in terms of linguistic communication: sounds and letters forming lexical units) used by the sender to encode a message according to the code (the grammar) of the code system (the language) that is used to communicate.

In the literature on general communication theory a clear distinction between message and utterance is not often formulated, unlike for linguistic communication by Cruse in (2) above. In some cases these terms would ostensibly be regarded as referential synonyms; compare for example Sebeok (2006: 44), who states that "[a] message is a sign, or consists of a string of signs". For this reason the definition of the concept message in (5) has been crafted for the purposes of the TLC and not quoted from existing communication theory literature. A further motivation for this step lies in the principle of expressibility, introduced by Searle (1969: 19) in speech act theory, which states that "whatever can be meant can be said." This principle is central to the TLC as it currently stands. ${ }^{3}$

A clear distinction between message and utterance is not only valid, but necessary, as more than one message can be encoded in an utterance. In fact, it will be shown in section 4 that at least four types of messages are encoded in an utterance.

In lexicographical communication, then, specific types of information (i.e. about lexical items) are constructed in specific types of messages that are encoded in specific types of utterances (i.e. lexicographic text segments) during the lexicographic process. During the dictionary consultation process, the target user locates and decodes the utterances to reconstruct the messages and derive the information, which is interpreted against the user's frame of refer- 
ence and then applied to the user situation.

To illustrate these terms, the following partial dictionary article will serve as example:

(6) book, $n$.

This partial article consists of three lexicographic utterances $\mathrm{LU}_{1}, \mathrm{LU}_{2}$ and $\mathrm{LU}_{3}$, in the form of separate (uncategorised) text segments:

(7) a. $\mathrm{LU}_{1}=$ "book"

b. $\mathrm{LU}_{2 \backslash \mathrm{LU} 1}=", "$

c. $\mathrm{LU}_{3 \backslash \mathrm{LU} 1}=$ "n."

("LU $\mathrm{L}_{\mathrm{x} \backslash \mathrm{LUy}}$ " reads " $\mathrm{LU}_{\mathrm{x}}$, as addressed at $\mathrm{LU}_{\mathrm{y}}$. ")

Lexicographer $l$ wants to convey information $\mathrm{i}_{l}$, that the lexical item book is a noun, to target user $u$. The lexicographer constructs this information in lexicographic message $\mathrm{LM}_{l}$ :

(8) $\quad \mathrm{LM}_{l}=$ The lexical item book is a noun.

Therefore, $\mathrm{i}_{l}$ is constructed in $\mathrm{LM}_{l}$ for the lexicographer:

(9) $\mathrm{i}_{l}\left[\mathrm{LM}_{l}\right]$

(" $x[y]$ " reads " $x$ is constructed/encoded in $y$ or reconstructed/decoded from $y "$.)

This message is then encoded in lexicographic utterance $\mathrm{LU}_{3 \backslash \mathrm{LU} 1}$ in the partial dictionary article above:

(10) $\quad \mathrm{LU}_{3 \backslash \mathrm{LU1}}=$ "n."

Therefore, $\mathrm{LM}_{l}$ is encoded in $\mathrm{LU}_{3 \backslash \mathrm{LU} 1}$ for the lexicographer: ${ }^{4}$

$$
\mathrm{LM}_{l}\left[\mathrm{LU}_{3 \backslash \mathrm{LU} 1}\right]
$$

Therefore:

(12) $\mathrm{i}_{l}\left[\mathrm{LM}_{l}\left[\mathrm{LU}_{3 \backslash \mathrm{LU} 1}\right]\right]$

Target user $u$ locates $\mathrm{LU}_{3 \backslash \mathrm{LU} 1}$, decodes it and reconstructs $\mathrm{LM}_{u}$ :

(13) $\quad \mathrm{LM}_{u}=$ The lexical item book is a noun.

Therefore, $\mathrm{LM}_{\mathcal{u}}$ is decoded from $\mathrm{LU}_{3 \backslash \mathrm{LU} 1}$ for target user $u$ :

(14) $\mathrm{LM}_{u}\left[\mathrm{LU}_{3 \backslash \mathrm{LU} 1}\right]$

Target user $u$ reconstructs from $\mathrm{LM}_{u}$ information $\mathrm{i}_{u}$, that the lexical item book is a noun, and then applies this information to user situation $\mathrm{s}_{u}$, which constitutes 
effect $\mathrm{E}_{u}$. Therefore:

(15) $\quad \mathrm{i}_{u}\left[\mathrm{LM}_{u}\left[\mathrm{LU}_{3 \backslash \mathrm{LU} 1}\right]\right] \rightarrow \mathrm{E}_{u}$

(" $x \rightarrow y$ " reads "From $x$ follows (naturally) consequence $y$ ".)

The sequence of lexicographical communication is therefore:

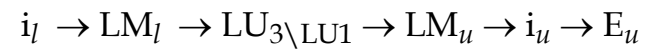

This simple example represents the ideal case in user-centred lexicography: $\mathrm{i}_{l}=$ $\mathrm{i}_{u}$, which satisfies user need $\mathrm{n}_{u}$ in user situation $\mathrm{s}_{u}$, as is evidenced by effect $\mathrm{E}_{u}$.

Generally speaking, contemporary lexicographical theories use the term data to refer to text segments and information to refer to the "information" that the target user derives from decoding the text segments (cf. Tarp 2008: 97-100). It would seem, however, that data and information in these theories refer almost exclusively to the relevant facts about the treated lexical items. This view seems to coincide with the somewhat limited view of the functions of language that Brown and Yule (1983: 2) claim linguists and linguistic philosophers generally adopt, namely "that the most important function is the communication of [data]". However, as the definition of the term information in communicative terms above suggests, the concept encapsulates more than factual knowledge and can crucially also include informational dimensions like attitudes, emotions, etc. that cannot necessarily be expressed in terms of data. It seems, then, that the denotation of the term information is slightly broader in the TLC than in contemporary lexicographical theories. ${ }^{5}$

Nevertheless, the TLC may not ignore the valid rationale for the distinction between data and information in these theories, one that is also supported by communication theory (albeit without using the same terms). For this reason, information constructed in an $\mathrm{LM}_{l}$ by the lexicographer is referred to above as "information" $\left(=\mathrm{i}_{l}\right)$, and information reconstructed from an $\mathrm{LM}_{u}$ by the target user as "information ${ }_{u} "\left(=\mathrm{i}_{u}\right)$. A parallel distinction applies to $\mathrm{LM}_{l} \mathrm{~s}$ and $\mathrm{LM}_{\mathcal{u}}$ s.

\section{Types of information, informational dimensions and types of lexico- graphic messages}

\subsection{Types of information}

When information as a phenomenon in the TLC is considered, a distinction between information categories (also referred to as information types) and informational dimensions is necessary.

Lexicographical information can be categorised into types like information about parts of speech of lexical items, morphological information about plural formations of lexical items, information about the meaning of a lexical item, etc. 
The just mentioned types of information have in common that they can all be regarded as types of factual information, as opposed to, for example, types of affective information. They therefore belong to one and the same informational dimension.

\subsection{Informational dimensions and types of lexicographic messages}

Janssen (1996) and Steehouder et al. (1999) describe the elements of communication in the business or professional situation, as opposed to communication in informal and intimate situations on the one hand and mass communication on the other hand. In so doing, Steehouder et al. (1999: 24) introduces four types of messages in an utterance. Janssen introduces identical types, but at the information stage of the communication sequence. To distinguish these from the (subordinate) information types as described in 4.1 above, they will be referred to in the TLC as informational dimensions. The types that Janssen (1996) and Steehouder et al. (1999) introduce are adapted below for the purposes of lexicographical communication. The following four dimensions will be discussed:

- Referential information (4.2.1): the factual information encoded in an LM;

- Expressive information (4.2.2): information about the lexicographer as sender;

- Relational information (4.2.3): information about how the lexicographer regards the target user;

- Appeal information (4.2.4): information about the purpose(s) of an LU.

\subsubsection{Informational dimension: referential information}

Referential information can be described as the factual information encoded in a lexicographic message. (This seems to be what at least the function theory refers to as data, but data in the function theory are in fact LUs in the TLC. ${ }^{6}$ ) Consider a dictionary article with the lemma vuvuzela. The lemma sign is $\mathrm{LU}_{4}$, in which at least two lexicographic messages, $\mathrm{LM}_{l}-1$ and $\mathrm{LM}_{l}-2$, are encoded. In both $\mathrm{LM}_{l} \mathrm{~s}$ referential information $l=$ ref. $\left.\mathrm{i}_{l}\right)$ is constructed and therefore both $\mathrm{LM}_{l} \mathrm{~s}$ are of the type referential $\mathrm{LM}_{l}\left(=\right.$ ref.LM $\left.\mathrm{LM}_{l}\right)$. For analytical purposes the following formal representation can be offered7:

$$
\begin{aligned}
\mathrm{LU}_{4}= & \text { lemma sign: "vuvuzela" } \\
& \text { ref.LM } \mathrm{LM}_{l}-1\left[\mathrm{LU}_{4}\right] \text { : This dictionary article contains information about } \\
& \text { the lexical item vuvuzela. } \\
& \text { ref.. } \mathrm{i}_{l}-1\left[\mathrm{ref} . \mathrm{LM}_{l}-1\left[\mathrm{LU}_{4}\right]\right]=\text { This dictionary article contains } \\
\text { information about the lexical item vuvuzela. } & \\
& \text { ref.LM } \mathrm{LM}_{l}-2\left[\mathrm{LU}_{4}\right]=\text { The lexical item vuvuzela is spelt v-u-v-u-z-e-l-a. }
\end{aligned}
$$


ref.i $i_{l}-2\left[\right.$ ref. $\left.L_{l}-2\left[\mathrm{LU}_{4}\right]\right]=$ The lexical item vuvuzela is spelt v-u-v-u-z-e-l-a.

In following the definition of message in (5) and therefore also the principle of expressibility as applied to the TLC, the value of $\mathrm{i}_{l^{-}} x$ is identical to that of $\mathrm{LM}_{l^{-}}$ $x$, since $\mathrm{LM}_{l}-x$ is the expression of $\mathrm{i}_{l}-x$. The statement of the value of $\mathrm{i}_{l}-x$ is therefore redundant in further formal representations, and is henceforth omitted; the value is represented by $\mathrm{LM}_{l}-x$.

The value of each ref.LM $\mathrm{LM}_{l}$ can be evaluated qualitatively and quantitatively in terms of referential criteria like accuracy and completeness. Such evaluations apply by extension to the relevant LUs as the observable manifestations of the messages, for which Grice's maxims in (3) could be adopted. In semantic terms the ref.LM $\mathrm{LM}_{l} \mathrm{~s}$ could be referred to as the propositions of an LU (cf. e.g. Lyons 1977, Cruse 2011), and in terms of speech act theory they could be regarded as locutionary speech acts (cf. e.g. Levinson 1983, Cruse 2011).

\subsubsection{Informational dimension: expressive information}

A (lexicographic) utterance not only conveys referential information, but also information about the sender/lexicographer. This information belongs to the informational dimension of expressive information (= exp.i), and a unit of expressive information is constructed in an expressive LM (= exp.LM). By means of the LUs in a dictionary, a particular identity of the lexicographer (and/or publisher) is conveyed to the user. In business communication a distinction is made between a corporate identity and a corporate image. Fielding and Du Plooy-Cilliers (2014: 285) describe corporate identity as "everything that is distinctive, lasting and central to an organisation that gives it a particular character" and corporate image as "how the public views the organisation." Applying this distinction to lexicographical communication, the exp.LMs that the lexicographer encodes in LUs can be regarded as expressions of the lexicographer's identity, while the exp.LMs that the user decodes from LUs collectively form the image of the lexicographer with the user.

In the development of a dictionary plan and style guide, the lexicographer and publisher should determine what type of identity they would like to convey about themselves to the target user and formulate it in a set of expressive style guide policy statements (= exp.SPS\{n\}). (Identity is conveyed at various textual and structural levels in the dictionary.) This facet is perhaps less obvious in document types that Carstens and Van de Poel (2010:68) refer to as informative referential texts (among which they include dictionaries), since the genres belonging to this type of text are seemingly designed to convey referential information and not to express any particular identity of the sender. However, the text type does not preclude the fact that expressive information is also conveyed, even if the sender is not aware of this fact or has not established an identity that he/she would like to convey. ${ }^{8}$ Compare Moon (2014) for a detailed 
discussion of this type of information in learners' dictionaries from the perspective of critical lexicography. (Publishers are generally acutely aware of this informational dimension, especially in planning the marketing of their dictionaries. ${ }^{9}$ )

According to Steehouder et al. (1999), receivers are sensitive to the expressive message(s) in an utterance and are often involuntarily influenced by them. Both the sender's and the receiver's frame of reference (= FoR) come into play here, since messages are constructed and encoded in utterances against the sender's FoR, and utterances are decoded and messages reconstructed against the receiver's FoR. This point will become pertinent below.

Janssen (1996) and Steehouder et al. (1999) identify the following characteristics of senders, among others, that can be regarded as expressive information that contribute to senders' identities and images: expert, novice, serious, self-assured, unsure, open, closed, arrogant, humble, formal, informal, longwinded, curt, grumpy, sympathetic, helpful, competent, incompetent, objective, subjective, credible. ${ }^{10}$ From a lexicographical perspective characteristics like prescriptive, descriptive and proscriptive (cf. Bergenholtz 2003) could be added. The list is not exhaustive.

Expressive information also conveys the sender's norms and values (as parts of the sender's identity), which may or may not be representative of the relevant speech community's or the target user's social and personal norms and values (cf. also Moon 2014). To relate this informational dimension to lexicographical communication, compare Van Sterkenburg (2003: 8), who comments in reference to the general monolingual dictionary that

[i]t also serves as a guardian of the purity of the language, of language standards and of moral and ideological values because it [i.e. the lexicographer - HLB] makes choices, for instance in the words that are to be described.

When exp. $i_{u}$ is identical to the norms and values of the user, or it is the exp.i that the user expects to derive from lexicographical communication, usually no observable effect would be registered with the user. Effects are more readily observed when exp. $\mathbf{i}_{u}$ does not conform with the user's norms and values or is not the exp.i that the user expects to derive. For this reason the scope of effects in figure 1 is indicated by a dotted line. This aspect is central to the hypotheses in (27) to (29) below and in the discussion of unintentional effects in section 5.

Generally, professional lexicographer $l$ wants to communicate at least the following exp.LM $\mathrm{LM}_{l}$ to the user, which follow from the relevant SPS $\{\mathrm{n}\}$ :

a. $\left(\right.$ SPS- $\left.1 \rightarrow \exp . \mathrm{LM}_{l}-1\right)=l$ has zero bias.

b. (SPS-2 $\left.\rightarrow \exp \cdot \mathrm{LM}_{l}-2\right)=l$ is objective.

These exp. $\mathrm{LM}_{l} \mathrm{~s}$, among others, are assumed here to be identical to the exp. $\mathrm{LM}_{u} \mathrm{~s}$ that users generally expect to decode from LUs in professional dictionaries. ${ }^{11}$ They may therefore be regarded as default exp. $\mathrm{LM}_{u} \mathrm{~s}$ : The user will only realise their value if exp.LM $\mathrm{L}_{u} \mathrm{w}$ with different or negating values replace them. 
Consider the following lexical paraphrase of the lemma vuvuzela, taken from the online Collins English Dictionary:

(19) $\mathrm{LU}_{5}=$ lexical paraphrase: "an elongated plastic instrument that football fans blow to make a loud noise similar to the trumpeting of an elephant"

$\mathrm{LU}_{5}$ could be partially decoded as follows:

(20) ref. $\mathrm{LM}_{\mathcal{u}}-1\left[\mathrm{LU}_{5}\right]=\mathrm{A}$ vuvuzela is an instrument.

ref. $\mathrm{LM}_{\mathcal{u}}-2\left[\mathrm{LU}_{5}\right]=\mathrm{A}$ vuvuzela is made of plastic.

ref. $\mathrm{LM}_{u}-3\left[\mathrm{LU}_{5}\right]=\mathrm{A}$ vuvuzela has an elongated form

ref. $\mathrm{LM}_{u}-\mathrm{n}\left[\mathrm{LU}_{5}\right]=$ The loud noise of a vuvuzela is similar to the trumpeting of an elephant.

exp. $\mathrm{LM}_{\mathcal{u}}-1\left[\mathrm{LU}_{5}\right]=l$ is not biased.

$\exp \cdot \mathrm{LM}_{u}-2\left[\mathrm{LU}_{5}\right]=l$ is objective.

In this case

(21) a. exp. $\mathrm{LM}_{l}-1\left[\mathrm{LU}_{5}\right]=\exp \cdot \mathrm{LM}_{u}-1\left[\mathrm{LU}_{5}\right]$

b. $\exp \cdot \mathrm{LM}_{l}-2\left[\mathrm{LU}_{5}\right]=\exp \cdot \mathrm{LM}_{\mathcal{u}}-2\left[\mathrm{LU}_{5}\right]$

Consider, now, the following lexical paraphrase, one of several addressed at the lemma vuvuzela in the crowd-sourced online Urban Dictionary:

(22) $\mathrm{LU}_{6}=$ lexical paraphrase: "A mind-numbing torture device made of cheap, brightly colored [sic] plastic. It resembles a horn but its pitch cannot be changed. It is being used during the 2010 World Cup in South Africa."

$\mathrm{LU}_{6}$ could be partially decoded as follows:

(23) ref. $\mathrm{LM}_{u}-1\left[\mathrm{LU}_{6}\right]=\mathrm{A}$ vuvuzela is a mind-numbing torture device.

ref. $\mathrm{LM}_{u^{u}}-2\left[\mathrm{LU}_{6}\right]=\mathrm{A}$ vuvuzela is made of cheap, brightly coloured plastic.

ref. $\mathrm{LM}_{u}-3\left[\mathrm{LU}_{6}\right]=\mathrm{A}$ vuvuzela resembles a horn.

ref. $\mathrm{LM}_{u}-4\left[\mathrm{LU}_{6}\right]=\mathrm{A}$ vuvuzela's pitch cannot be changed.

ref. $\mathrm{LM}_{u}-5\left[\mathrm{LU}_{6}\right]=\mathrm{A}$ vuvuzela is being used during the 2010 World Cup in South Africa.

exp. $\mathrm{LM}_{u}-1\left[\mathrm{LU}_{6}\right]=l$ is biased.

exp. $\mathrm{LM}_{u}-2\left[\mathrm{LU}_{6}\right]=l$ is subjective.

exp. $\mathrm{LM}_{u}-3\left[\mathrm{LU}_{6}\right]=l$ dislikes vuvuzelas.

exp. $\mathrm{LM}_{u}-4\left[\mathrm{LU}_{6}\right]=l$ is offensive.

exp. $\mathrm{LM}_{u}-5\left[\mathrm{LU}_{6}\right]=l$ is unfriendly.

...

Kosch (2013) raises the notion of user expectation in dictionaries, which can either be adapted for the TLC or utilised in its current conceptualisation. It is 
important to recognise that any $\mathrm{LM}_{\mathcal{u}^{-}} x$ that is decoded from an $\mathrm{LU}_{\mathrm{y}}$ follows from the user's frame of reference $\left(=\mathrm{FoR}_{u}\right)$, which contains the user's relevant norms, values, attitudes, etc. ${ }^{12}$ This important relation can be formalised as follows:

$$
\mathrm{FoR}_{u} \rightarrow \mathrm{LM}_{u^{-}} x\left[\mathrm{LU}_{\mathrm{y}}\right]
$$

The value of $\mathrm{LM}_{u}-x\left[\mathrm{LU}_{\mathrm{y}}\right]$ is then measured against the user's set of user expectations $\left(=\mathrm{Xpt}_{u}\{\mathrm{n}\}\right)$. If these expectations are fulfilled, non-observable effects (or zero-effects) can be predicted because the users would generally not display a response when their $\mathrm{Xpt}_{u}\{\mathrm{n}\} \mathrm{s}$ are fulfilled. However, if they are not fulfilled, certain unpredictable and observable effects will occur.

In the case of exp.LM ${ }_{u}-1 . .5\left[\mathrm{LU}_{6}\right]$ in (23), it seems that SPS-1,2 do not apply to Urban Dictionary, as no gatekeeping appears to be in operation, judging by the contents of some of the lexical paraphrases. ${ }^{13}$ Therefore, the normal subset of expressive user expectations ( $\left.=\exp . \mathrm{Xpt}_{\mathrm{u}}\{\mathrm{n}\}\right)$ is not fulfilled, which leads to a number of unpredictable effects $\left(=\exp . \mathrm{E}_{u}-1 . . \mathrm{n}\right)$ that follow from exp.LM $\mathrm{M}_{u}$ s. This can be represented in the following formalisation:

(25) If exp.LM $\mathrm{LM}_{u}-1 . .5\left[\mathrm{LU}_{6} \in\right.$ Urban Dictionary $] \rightarrow \exp . \mathrm{E}_{u}-1 . . \mathrm{n}$ and exp.LM $\mathrm{LM}_{u}-1 . .5\left[\mathrm{LU}_{6} \in\right.$ Urban Dictionary $]<\exp . \mathrm{Xpt}_{u}\{\mathrm{n}\}$ then exp. $\mathrm{E}_{u}-1 . . \mathrm{n}=$ unpredictable exp. $\mathrm{E}_{\mathcal{u}}-1 . . \mathrm{n}$

(" $x \in y$ " reads " $x$ is/as an element of (set) $y " ;$ " $x<y$ " reads " $x$ does not fulfil the requirements of (is less than) $y$ "; " $x\{\mathrm{n}\}$ " reads "a set that contains elements of the type $x^{\prime \prime}$.)

While:

(26) If exp.LM $\mathrm{LM}_{u}-x\left[\mathrm{LU}_{\mathrm{x}} \in\right.$ professional dictionary $\left.D\right] \rightarrow$ exp. $\mathrm{E}_{u}-1 . . \mathrm{n}$ and exp.LM ${ }_{u}-x\left[\mathrm{LU}_{\mathrm{x}} \in\right.$ professional dictionary $\left.D\right] \cong \exp . \mathrm{Xpt}_{u}\{\mathrm{n}\}$ then exp. $\mathrm{E}_{u}-1 . . \mathrm{n}=\varnothing$

(" $x \cong y$ " reads " $x$ fulfils the requirements of (is congruent to) $y "$ "; "Ø" reads "zero (i.e. non-observable)".)

From these expressions and the preceding discussion, the TLC could generate the following hypotheses: ${ }^{14}$

$$
\begin{array}{ll}
\mathrm{H}_{1}: \quad \text { If exp. } \mathrm{LM}_{\mathcal{u}}-x\left[\mathrm{LU}_{\mathrm{z}}\right] \rightarrow \exp . \mathrm{E}_{\mathcal{u}^{-}}-. . \mathrm{n} \\
\text { and exp.LM } \\
\text { then exp. } \mathrm{E}_{\mathcal{u}^{-}}-1 . . \mathrm{L}=\varnothing
\end{array}
$$

Conversely:

$$
\begin{aligned}
& \mathrm{H}_{2}: \quad \text { If exp. } \mathrm{LM}_{\mathcal{U}^{-}} x\left[\mathrm{LU}_{\mathrm{z}}\right] \rightarrow \exp . \mathrm{E}_{\mathcal{u}^{-}}-1 . . n \\
& \text { and exp. } \mathrm{E}_{u}-1 . . \mathrm{n}=\varnothing \\
& \text { then } \exp . \mathrm{LM}_{u}-x\left[\mathrm{LU}_{z}\right] \cong \exp . \mathrm{Xpt}_{u}\{\mathrm{n}\}
\end{aligned}
$$


And:

$$
\begin{aligned}
& \mathrm{H}_{3}: \quad \text { If } \exp . \mathrm{LM}_{\mathcal{u}^{-}} x\left[\mathrm{LU}_{\mathrm{z}}\right] \rightarrow \exp . \mathrm{E}_{\mathcal{u}^{-}}-1 . . \mathrm{n} \\
& \text { and exp. } \mathrm{E}_{u}-1 . . \mathrm{n} \neq \varnothing \\
& \text { then exp. } \mathrm{LM}_{\mathcal{u}}-x\left[\mathrm{LU}_{\mathrm{z}}\right]<\exp . \mathrm{Xpt}_{u}\{\mathrm{n}\}
\end{aligned}
$$

$\mathrm{H}_{2}$ and $\mathrm{H}_{3}$ can be expressed in natural language as follows:

(30) $\mathrm{H}_{2}$ : If certain expressive user effects follow from a certain expressive LM decoded from a certain LU, and these expressive user effects are zero-effects, it follows that the expressive LM fulfils the set of expressive user expectations.

$\mathrm{H}_{3}$ : If certain expressive user effects follow from a certain expressive LM decoded from a certain LU, and these expressive user effects are non-zero-effects, it follows that the expressive LM does not fulfil the set of expressive user expectations.

Effects (and zero-effects) are addressed in section 5.

The ref. $\mathrm{LM}_{u}-1 . .5\left[\mathrm{LU}_{6}\right]$ have not been addressed, but for the purposes of the current discussion they can be regarded as irrelevant, because (a) this section deals with exp.LMs only, and (b) they are probably of lesser importance when the purpose(s) of $\mathrm{LU}_{6}$ are considered (cf. 4.2.4), although the truth of the propositions could be questioned.

The analyses of $\mathrm{LU}_{5,6}$ in (20) and (23) above have demonstrated that the lexicographer does encode something of him-/herself in LUs (and obviously deliberately so in the case of $\mathrm{LU}_{6}$ ). It is important to recognise this aspect in professional lexicography and consequently to devote the necessary time and energy during the development of the dictionary plan and style guide to formulate appropriate exp.SPS $\{\mathrm{n}\}$ pertaining to the desired identity of the lexicographer, the dictionary and the publisher. Even in the comparatively simple $\mathrm{LU}_{3}$ "n." is encoded the default exp. $\mathrm{LM}_{l}\left[\mathrm{LU}_{3}\right]=" l$ is an authority on the treated lexicon."

The propositions of exp.LMs can be evaluated qualitatively and quantitatively in terms of appropriateness for the user situation. In assigning values during formal evaluation, the evaluator should be able to validate these values in terms of pre-established criteria formulated against the background of the purpose(s) of the relevant dictionary, the target user and the user situation.

\subsubsection{Informational dimension: relational information}

In addition to information about the sender that is derivable from his/her utterances, Steehouder et al. (1999) and Janssen (1996) maintain that information about how the sender regards the receiver can also be derived from an utterance. This is referred to as relational information (= rel.i). In lexicographical 
communication, LMs in or from which rel.i is constructed or reconstructed are accordingly called relational LMs (= rel.LMs). Relational messages can be overtly but also very subtly (and unintentionally) encoded in utterances. Like all types of messages, relational messages are decoded by receivers against their FoRs. Any rel. $\mathrm{LM}_{u}$ results in one or more relational user effects (= rel. $\left.\mathrm{E}_{\mathcal{u}}-1 . . \mathrm{n}\right)$ :

$$
\text { rel. } \mathrm{LM}_{u}-x \rightarrow \text { rel. } \mathrm{E}_{\mathcal{u}}-1 . . \mathrm{n}
$$

Steehouder et al. (1999) names four types of suppositions about the receiver that can influence communication. These are suppositions about

- $\quad$ the receiver's knowledge;

- the receiver's language skills;

- $\quad$ the receiver's norms, values, preferences and tastes; and

- $\quad$ the relation between the sender and the receiver.

Janssen (1996) identifies the following characteristics of the receiver as assigned by the sender that can be regarded as instances of rel.i following from the above suppositions: equal, superior, subordinate, rational, naïve, cooperative, stubborn, friend, enemy, intelligent, stupid. The list is not exhaustive.

As far as lexicographical communication is concerned, at least the first three types of suppositions above relate to the sociology of the dictionary user (cf. Wiegand 1977, Hartmann 1989). The relevant values should be based on empirical user research and be represented as elements of the target user profile (in terms of rel.SPS $\{\mathrm{n}\}$ ) when a dictionary is planned, and should not be left to supposition (cf. e.g. Tarp (2008)).

As in the case of exp.LMs, rel.LMs are encoded in and decoded from LUs against the FoRs of the lexicographer and user respectively. Given the requirement of a target user profile in the planning of a dictionary, the lexicographer should be aware of the target user's FoR. Nevertheless, the lexicographer can (unintentionally) encode rel.LM $\mathrm{LM}_{l}-. . \mathrm{n}$ in LUs based upon suppositions about the perceived relation between the lexicographer and the sender which may not follow from a rel.SPS $\{\mathrm{n}\}$ and do not fulfil the target user's set of relational expectations ( $\left.=\operatorname{rel} . \mathrm{Xpt}_{u}\{\mathrm{n}\}\right)$. It can also be the case that in following the dictionary plan or style guide, the lexicographer (unintentionally) encodes a rel.LM $\mathrm{LM}_{l}$ in an LU that does not fulfil the target user's rel.Xpt $\{n\}$. Obviously, it may also be the case that the user decodes rel.LMs from LUs that the lexicographer did not intend to encode in them. The question is then whether $\mathrm{FoR}_{l}=\mathrm{FoR}_{u}$ with regard to the relevant elements in the relevant instance.

Louw and Beyer (in preparation) report that during empirical user research for a school dictionary

(32) some of the respondents were of the opinion that a dictionary containing FSDs [full-sentence definitions - HLB] would be a "dumbed down" version of a "real" dictionary and would in effect "talk down" to the user. 
The respondents were not the primary target users (i.e. learners), but a number of their teachers. In so far as their responses could be regarded as representative of the primary target user group ${ }^{15}$ and therefore as observable relational user effects $\left(=\right.$ rel. $\left.E_{u}-1 . . n\right)$, at least the following rel. $\mathrm{LM}_{u} \mathrm{~s}$ can be derived as decoded by some of them from any particular full-sentence lexical paraphrase $\left(\mathrm{LU}_{\mathrm{x}}\right)$ :

(33) $\quad$ rel. $\mathrm{LM}_{u}-1\left[\mathrm{LU}_{\mathrm{x}}\right]=u$ is stupid.

rel.LM ${ }_{u}-2\left[\mathrm{LU}_{\mathrm{x}}\right]=u$ is not capable of using a "real" dictionary.

rel. $\mathrm{LM}_{u}-3\left[\mathrm{LU}_{\mathrm{x}}\right]=u$ is socially inferior.

(While exp.LMs are expressed as propositions with $l$ as the subject of the propositional sentence, rel.LMs are expressed with $u$ as the subject, i.e. as propositions representing the lexicographer's view of the target user.)

It is to be expected that the rel.LMs encoded by the lexicographer in any LU are elements of the relevant rel.SPS $\{\mathrm{n}\}$, and that rel.:LM ${ }_{u}-1,2,3$ above as decoded by the user from that LU are not elements of this rel.SPS $\{n\}$. Therefore, the relational LMs encoded by the lexicographer in the LU are not equal to rel. $\mathrm{LM}_{u}-1,2,3$ above as decoded by the user from the LU. rel.E $\mathrm{E}_{u}-1 . . \mathrm{n}$ follow from rel.LM $\mathrm{L}_{u}-1,2,3$ above as decoded from the $\mathrm{LU}$ by the user, and a number of intentional relational effects $\left(=\right.$ rel.E $E_{l}-1 . . n$ ) ideally follow from the rel.LMs encoded by the lexicographer in the LU. Therefore, the rel. $E_{u}-1 . . n$ that could be observed with the users are not elements of rel. $E_{\{}\{n\}$ intended by the lexicographer, as elements of the rel.SPS\{n\}. (In non-technical terms: The lexicographer did not intend for rel. $\mathrm{LM}_{\mathcal{u}}-1,2,3$ above to be decoded from $\mathrm{LU}_{\mathrm{x}}$.) This explanation can be formalised in the following propositional formulas:

$$
\begin{aligned}
& \text { rel.LM }{ }_{l}-1 . . n\left[L_{\mathrm{x}}\right] \in \operatorname{rel} . S P S\{\mathrm{n}\} \\
& \text { rel.LM }{ }_{u}-1,2,3\left[\mathrm{LU}_{\mathrm{x}}\right] \notin \text { rel.SPS }\{\mathrm{n}\} \\
& \therefore \text { rel.LM }{ }_{l}-1 . . \mathrm{n}\left[\mathrm{LU}_{\mathrm{x}}\right] \neq \text { rel. } \mathrm{LM}_{u}-1,2,3\left[\mathrm{LU}_{\mathrm{x}}\right] \\
& \text { If rel. } \mathrm{LM}_{\mathcal{u}}-1,2,3\left[\mathrm{LU}_{\mathrm{x}}\right] \rightarrow \text { rel.E } \mathrm{E}_{\mathcal{u}}-1 . . \mathrm{n} \\
& \text { and rel.LM }{ }_{l}-1 . . \mathrm{n}\left[\mathrm{LU}_{\mathrm{x}}\right] \rightarrow \text { rel. } \mathrm{E}_{l}-1 . . \mathrm{n} \\
& \text { rel. } \mathrm{E}_{u}-1 . . \mathrm{n} \neq \text { rel. } \mathrm{E}_{l}-1 . . \mathrm{n}
\end{aligned}
$$

Still, rel.:LM ${ }_{u}-1,2,3$ were decoded, which resulted in rel.E $\mathrm{E}_{u}-1 . . \mathrm{n}$ reported informally in (32). This case illustrates that, even with the best (educational) intentions, the rel. $\mathrm{LM}_{l} \mathrm{~s}$ encoded in an LU are not necessarily equal to the rel.LM $\mathrm{L}_{\mathcal{L}} \mathrm{s}$ decoded from the same LU. This demonstrates the necessity of establishing the target user's FoR empirically. Following this, the dictionary plan and/or style guide should formulate a rel.SPS $\{\mathrm{n}\}$ relating to the desirable rel.LM $\mathrm{L}_{l} \mathrm{~s}$ to be encoded in LUs, as was alluded to earlier.

Hypotheses similar to those formulated with regard to exp.LMs in (27) to (29) in section 4.2.2 can be formulated for rel.LMs and the set of relational user

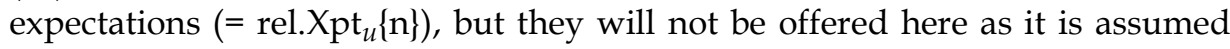
that those in section 4.2.2 sufficiently demonstrate the relevant potential. 
As is the case with exp.LMs, the values of rel.LMs can be evaluated qualitatively and quantitatively in terms of appropriateness for the user situation, following from $\mathrm{FoR}_{u}$. In assigning values during formal evaluation, the evaluator should be able to validate these values in terms of pre-established criteria formulated against the background of the purposes of the relevant dictionary, the target user and the user situation.

At this point it should be recognised that exp.SPS $\{\mathrm{n}\}$ and rel.SPS $\{\mathrm{n}\}$ pertaining to a particular dictionary $D$ constitute the identity of the lexicographer/ publisher (= ID.lex $l$ ) to be encoded in the dictionary (through its LUs), while the exp. $\mathrm{LM}_{u}-1 . . \mathrm{n}$ and rel.LM $\mathrm{LM}_{u}-1 . . \mathrm{n}$ decoded from the set of LUs in dictionary $D$ by the user contribute to the image (= IM.lex ${ }_{u}$ ) of the lexicographer/publisher pertaining to that dictionary:

$$
\begin{aligned}
& \text { a. }\left(\operatorname{ID} \cdot \operatorname{lex}_{l} \gg D\right)=(\exp . \operatorname{SPS}\{\mathrm{n}\} » D) \cup(\operatorname{rel} . S P S\{\mathrm{n}\} » D) \\
& \text { b. }\left(\operatorname{IM} \operatorname{lex}_{u^{»}} D\right)=\left(\exp \cdot \mathrm{LM}_{\mathcal{u}}\{\mathrm{n}\}[\mathrm{LU}\{\mathrm{n}\} \in D]\right) \cup\left(\operatorname{rel}^{\prime} \mathrm{LM}_{u}\{\mathrm{n}\}[\mathrm{LU}\{\mathrm{n}\} \in D]\right)
\end{aligned}
$$

(" $x » y$ " reads " $x$, which is associated with $y " ; x\{\mathrm{n}\} \cup y\{\mathrm{n}\}$ reads "the union of set $x$ and set $y^{\prime \prime}$.)

The image of the target user that is held by the lexicographer (= IM.usr $l$ ) is formed by rel.SPS $\{\mathrm{n}\}$ pertaining to the particular dictionary $D$ :

$$
\left(\operatorname{IM}_{\operatorname{usr}}{ }^{» D}\right)=(\text { rel.SPS }\{\mathrm{n}\} » D)
$$

\subsubsection{Informational dimension: appeal/purpose information}

It is generally agreed that communication takes place with some purpose in mind (cf. Steinberg 2007). Appeal information is information about the purpose(s) of an utterance, and in lexicographical communication this type of information is constructed in appeal LMs (= aim.LM-1..n).

Steehouder, et al. (1999) distinguishes five types of communicative purposes of utterances, as follows:

Table 1: Types of communicative purposes according to Steehouder et al. (1999: 26)

\begin{tabular}{|l|l|}
\hline Type of purpose & Purpose of the type of purpose \\
\hline Informative & To inform the receiver about facts. \\
\hline Instructive & To equip the receiver with a particular skill or set of skills. \\
\hline Persuasive & To influence the receiver's opinion or attitude about something. \\
\hline Motivational & To influence the receiver's behavioural intension, willingness. \\
\hline Affective & To influence the receiver's emotions. \\
\hline
\end{tabular}


This typology of communicative purposes seems to be expressed in terms of the effect that a particular instance of communication is meant to have on the receiver. Given that Steehouder et al. focuses on professional communication, it is a valid typology, since the purpose of an utterance is not always clear in these types of situations, or in any typical interpersonal communication situation for that matter. In many cases the receiver has to identify the underlying communicative purpose of an utterance in order to give it meaning.

For lexicography, however, discrete classes of text segments (i.e. LUs in terms of the TLC) with aligned purposes have been identified and described; compare, for example, the more than 400 classes in the lexicographical text theory of Wiegand $(1990,1996$, etc.) that are named according to their so-called genuine purpose. The text theory would refer to the class of $\mathrm{LU}_{3}$ above ("n.") as item giving the word class (Wiegand 1996: 149). The statement of the genuine purpose of a class of text segments therefore refers to what type of referential message is encoded therein, and not what the communicative purpose of the LU would be in terms of intended effects. In some cases the class name includes reference to specific additional information (i.e. except what the text segment would propositionally state) that the user would be able to derive from the relevant text segment; compare the class name item giving the definite article, which allows to ascertain the gender and the word class [sic] (Wiegand 1996: 148; my underlining - HLB).

In section 4.2.1 above it was stated that ref. $\mathrm{LM}_{l}-1 . . \mathrm{n}$ could in terms of the speech act theory in pragmatics be regarded as locutionary speech acts. Levinson (1983: 236) distinguishes as follows between the three types of acts that are performed with a linguistic utterance:

a. locutionary act: the utterance of a sentence with determinate sense and reference

b. illocutionary act: the making of a statement, offer, promise, etc. in uttering a sentence, by virtue of the conventional force associated with it (or with its explicit performative paraphrase)

c. perlocutionary act: the bringing about of effects on the audience by means of uttering the sentence, such effects being special to the circumstances of utterance

Illocutionary and perlocutionary acts could also be applied to lexicographical communication in the TLC. The so-called genuine purpose of a text segment (as expressed in its class name) in the text theory could be regarded as the illocutionary act of the relevant LU in speech act theory, while each communicative purpose of Steehouder, et al. in table 1 above could be regarded as a possible perlocutionary act of the relevant LU. Each of these speech acts can be assigned equivalents in the TLC, as indicated in the speech act theory analysis of $\mathrm{LU}_{3}$ in (10) in table 2: 
Table 2: Applying basic speech act theory (SAT) with TLC equivalents to an analysis of $\mathrm{LU}_{3}$

\begin{tabular}{|l|l|l|}
\hline \multicolumn{2}{|c|}{ LU $_{3 \backslash \text { LU1 }}=$ item giving the word class: "n." } \\
\hline $\begin{array}{l}\text { SAT: Locutionary act } \\
\text { TLC: Propositional contents }\end{array}$ & $\begin{array}{l}\text { SAT: } \text { Illocutionary act } \\
\text { TLC: Purpose }\end{array}$ & $\begin{array}{l}\text { SAT: Perlocutionary act } \\
\text { TLC: Intentional effect }\end{array}$ \\
\hline $\begin{array}{l}\text { The word class of lexical item } \\
\text { book is noun. }\end{array}$ & $\begin{array}{l}\text { Lexicographer } l \text { STATES that } \\
\text { the word class of lexical item } \\
\text { book is noun. }\end{array}$ & $\begin{array}{l}\text { User } u \text { is INFORMED of the fact } \\
\text { that the word class of lexical } \\
\text { item } \text { book is noun. }\end{array}$ \\
\hline
\end{tabular}

$\mathrm{LU}_{3}$ would therefore be analysed as follows in the TLC:

(38) $\quad \mathrm{LU}_{3 \backslash \mathrm{LU} 1}=$ item giving the word class: "n." ref. $\mathrm{LM}_{l}-1\left[\mathrm{LU}_{3 \backslash \mathrm{LU} 1}\right]=$ The word class of lexical item book is noun. $\operatorname{exp.LM}\left\{[\mathrm{n}\}\left[\mathrm{LU}_{3 \backslash \mathrm{LU} 1}\right] \in \exp . \mathrm{SPS}\{\mathrm{n}\}\right.$ rel.LM $\left\{\{\mathrm{n}\}\left[\mathrm{LU}_{3 \backslash \mathrm{LU} 1}\right] \in \operatorname{rel} . \mathrm{SPS}\{\mathrm{n}\}\right.$ $\operatorname{aim} \cdot \mathrm{LM}_{l}-1\left[\mathrm{LU}_{3 \backslash \mathrm{LU} 1}\right]=\boldsymbol{r}\left(\mathrm{ref}_{\mathrm{L}} \mathrm{LM}_{l}-1\left[\mathrm{LU}_{3 \backslash \mathrm{LU} 1}\right]\right)$

The notation convention used to express the value of aim. $\mathrm{LM}_{l}-1\left[\mathrm{LU}_{3 \backslash \mathrm{LU} 1}\right]$ follows Searle (1969: 31): " $\vdash$ " reads "STATEMENT". aim. $\mathrm{LM}_{l}-1\left[\mathrm{LU}_{3 \backslash \mathrm{LU1}}\right]$ therefore reads: "The first (and only) purpose of $\mathrm{LU}_{3}$, which is addressed at $\mathrm{LU}_{1}$, is to STATE that ref.LM ${ }_{l}-1\left[\mathrm{LU}_{3 \backslash \mathrm{LU} 1}\right] . "$ " (The intentional effect is not included in this analysis - cf. section 5 below.) If an LU's purpose is to STATE, such statement does not pertain exclusively to propositions formulated in ref. $\mathrm{LM}_{l}-1 . . \mathrm{n}$, for if this were the case, a distinction between ref.LMs and aim.LMs would be baseless. Applying speech act theory to linguistic communication, the utterance "It is cold in here" consists of the locutionary act (propositional content) "It is cold in here," while the illocutionary act could be "STATEMENT(It is cold in here)" or "REQUEST(Hearer closes the door)", among others. The valid illocutionary act would be determined by the discourse situation. In the same way a specific LU can also serve purposes other than merely stating its propositional contents. Each purpose would be encoded in a separate aim. $\mathrm{LM}_{l}$. Consider the text theory's item giving the definite article, which allows to ascertain the gender and the word class [sic] in the following dictionary article of a hypothetical German-English dictionary GED:

(39) Buch, das book

The dictionary article consists of four categorised LUs:

(40) a. $\mathrm{LU}_{7}=$ item giving the form of the lemma sign: "Buch"

b. $\mathrm{LU}_{8}=$ non-typographical structural marker: ","

c. $\mathrm{LU}_{9 \backslash \mathrm{LU7}}=$ item giving the definite article: "das"

d. $\mathrm{LU}_{10 \backslash \mathrm{LU7}}=$ item giving the lexical translation equivalent: "book" 
Assuming that the default set of propositions representing ID.lex ${ }_{l}$ is true by virtue of omitting exp.LM $\{\mathrm{n}\}$ and rel.LM $\{$ n $\}, \mathrm{LU}_{9}$ can be analysed as follows:

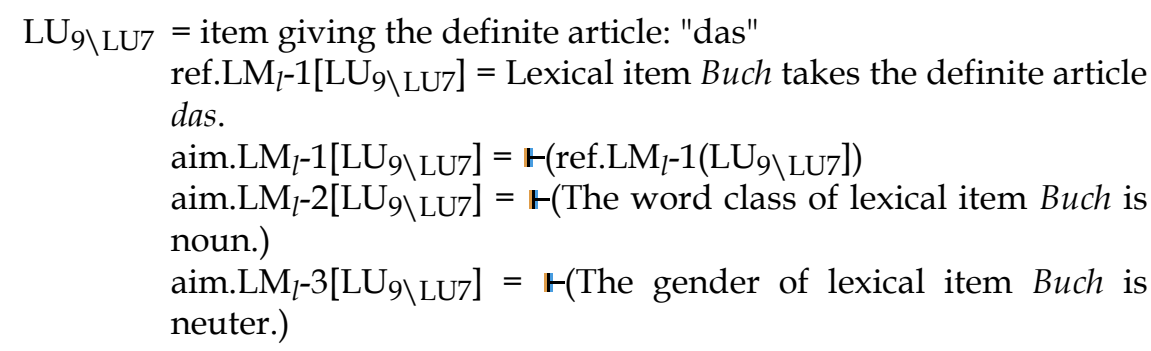

An aim. $\mathrm{LM}_{l}$ offers an answer to a potential user situation question $\left(=\mathrm{p} . \mathrm{SQ}_{u}\right)$ that expresses a particular potential information need of a target user in the typical user situation (following the principle of expressibility). In the ideal instance of lexicographical communication aim. $\mathrm{LM}_{u}-y$ (decoded from the relevant LU by the user) has the same value as aim. $\mathrm{LU}_{l-x}$ (encoded in the same LU by the lexicographer). Applying the formalisation in (41) to GED, an example could be:

$$
\begin{aligned}
& \text { p.SQ }{ }_{u} \backslash G E D \rightarrow \text { aim.LM }{ }_{u}-1\left[\mathrm{LU}_{9} \in G E D\right] \\
& \text { and } \left.\mathrm{p} . \mathrm{SQ}_{u} \backslash G E D=\text { ?(The word class of lexical item Buch is ...) }\right)^{16} \\
& \operatorname{aim} . \mathrm{LM}_{u}-1\left[\mathrm{LU}_{9} \in G E D\right]=\operatorname{aim} \cdot \mathrm{LM}_{l}-2\left[\mathrm{LU}_{9 \backslash \mathrm{LU7}} \in G E D\right]
\end{aligned}
$$

("p.SQ $\mathrm{SQ}_{u} \backslash G E D$ " reads "p.SQ $\mathrm{SQ}_{u}$ directed at dictionary GED"; "?(p)" reads "QUESTION (propositional function $p$ )" - cf. Searle (1969: 31).) $)^{17}$

The illocutionary force STATEMENT is not the only one that could apply to the purposes of LUs. Examples of at least two other types are:

(43) a. WARNING, e.g. when a stylistic-functional label ${ }^{18}$ like offensive is offered for the text production situation;

b. RECOMMENDATION, e.g. when the proscriptive approach is applied in a comment on a certain form in an inserted inner text for the text production situation.

Owing to limited space, the types of purposes (i.e. illocutions) will not be elaborated on here.

\section{Effects of lexicographical communication and lexicographic functions}

The terms effect and intentional effect have been used intuitively in earlier sections. These terms will now be clarified.

As the definition of the concept communication in (1) and the lexicographical communication model in figure 1 indicates, the sender communicates with the receiver in order to cause a particular effect with the receiver. Steinberg (2007: 21- 
22) distinguishes between two types of effects, i.e. intentional effects and unintentional effects, which are defined as follows:

(44) a. Intentional effects are the direct and predictable changes in the behaviour, opinion, attitudes or feelings of people in response to communication messages.

b. Unintentional effects are the indirect influences and unpredictable results of the communication.

Whether an instance of communication has resulted in intentional and/or unintentional effects can be determined by the receiver's feedback, which Steinberg (2007: 50) describes as "the response of participants [in communication] to each other." In lexicographical communication, however, it is possible that an LU could have a particular effect on the target user without that effect being observable, as was suggested in 4.2.2 above. ${ }^{19}$ Effects of lexicographical communication could therefore be classified into two further subtypes, namely observable effects and non-observable effects (or zero-effects). The basic typology can be presented in figure 2 below:

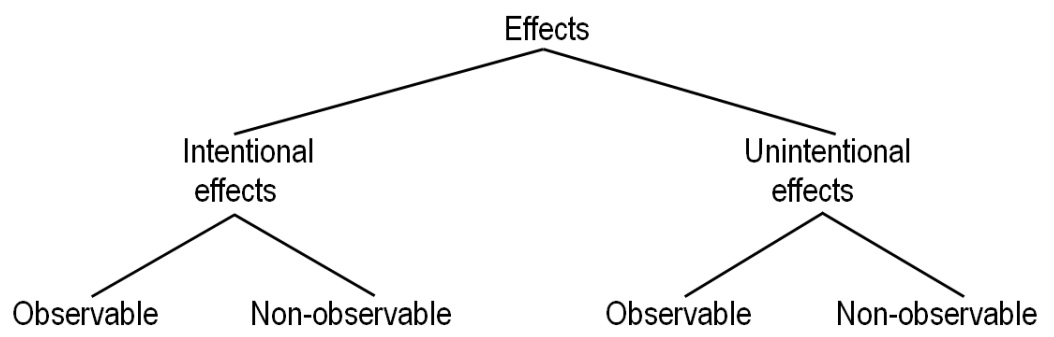

Figure 2: Basic typology of the effects of lexicographical communication

The type non-observable intentional effect might seem to be counter-intuitive, as the sender would normally like to observe some kind of effect in order to determine whether the communication effort has been successful. In lexicographical communication, however, a non-observable effect might in specific cases represent the intentional effect, which suggests that any observable effect would be an unintentional effect. This notion is evidenced in the hypotheses in (27) to (29) with regard to exp.LMs in 4.2.2 above. Considering the complexity of human behaviour, however, there is always the possibility that an unintentional effect could be non-observable. This might seem to challenge the hypotheses even before they could be tested. Nevertheless, citing the same human behaviour, it could be argued that the norm is known only by its exceptions. For example, if someone walked down the street completely naked (thereby violating the social norm that people wear clothes in public), there would predictably be an observable effect among (at least some of) the other 
people in the street exactly because of this exception. By contrast, and all other things being equal, the phenomenon of someone walking down the street while fully clothed would not result in any observable effect exactly because it conforms to the relevant social norm. The argument and example are of course not unproblematic, but it does raise the notion of norms, and this can be aligned to the set of user expectations $\left(=\mathrm{Xpt}_{u}\{\mathrm{n}\}\right)$ discussed in 4.2.2. $\mathrm{Xpt}_{u}\{\mathrm{n}\}$, as it pertains to exp.LM and rel.LM, could be regarded in lexicographical communication as products of socio-communicative norms following from $\mathrm{FoR}_{u} \mathrm{~s}$. It could therefore be reasonably assumed that if exp. $E_{u}-1 . . n$ and rel. $E_{u}-1 . . n$ are zero-effects, they result from conformation to the relevant socio-communicative norms and are therefore in fact intentional effects ( $\mathrm{cf.} \mathrm{H}_{2}$ in (28)). To cater for the possibility of non-observable unintentional effects resulting from non-conformity to the relevant socio-communicative norms, it is imperative to conduct empirical research in controlled environments where observable effects that might otherwise be non-observable are elicited by means of accepted scientific methods. Thorough empirical research into target users' collective FoR and resulting $\mathrm{Xpt}_{u}\{\mathrm{n}\}$ could also substantiate the conclusion that if exp. $\mathrm{E}_{u}-1 . . \mathrm{n}$ and rel.E $\mathrm{E}_{u}-1 . . \mathrm{n}$ are zero-effects, they are in fact intentional effects. In the same vein, if ref.LM $l^{-}$ 1..n in an LU are not challenged by unintentional ref. $\mathrm{E}_{\mathcal{u}}-1 . . n$, it can be reasonably assumed that the relevant ref.LM $\mathrm{LM}_{l}-. . \mathrm{n}$ are accepted by the user and are therefore true, correct, accurate, relevant, etc.

At this point the relation between $\mathrm{LM}_{u}$ and $\mathrm{E}_{u}$ can be formalised:
a. ref. $\mathrm{LM}_{u^{-}} x \rightarrow$ ref. $\mathrm{E}_{u^{-}}-y$
$(=$ referential user effects)
b. exp.LM $u^{-}-x \rightarrow$ exp. $E_{u^{-}} y \quad$ (= expressive user effects)
c. rel.LM $\mathrm{L}_{u^{-}} x \rightarrow$ rel. $\mathrm{E}_{u^{-}-y} \quad$ (= relational user effects)
d. $\operatorname{aim} . \mathrm{LM}_{u^{-}}-x \rightarrow \operatorname{aim}^{-E_{u}-y} \quad$ (= appeal user effects)

The aforementioned reasonable conclusions can also be formalised provisionally:

$$
\begin{aligned}
& \text { a. If } \mathrm{E}_{u^{-}}=\varnothing \\
& \mathrm{E}_{u^{-}}=\text {intentional } \mathrm{E}_{u^{-}}-x
\end{aligned}
$$

This would seem to suggest that the ideal effect of lexicographical communication is a zero-effect. This is not true, though. It should be borne in mind that ref. $\mathrm{E}_{u}$, exp. $\mathrm{E}_{u}$ and rel. $\mathrm{E}_{u}$ are not the primary $\mathrm{E}_{u}$ of lexicographical communication. They can be regarded as secondary effects or side-effect types, albeit effects of no lesser importance for successful communication. The $\mathrm{E}_{l}$ that lexicographical communication aims to yield, are aim. $\mathrm{E}_{l}$. In terms of the discussion in section 4.2.4 above, the communicative purposes presented by Steehouder et al. (1999) in table 1 (and partially applied in table 2) could be regarded as the types of aim. $E_{l}$, thus:

(47) As an intentional effect of lexicographical communication, user $u$ a. is INFORMED about a certain fact (cf. table 2); 
b. is INSTRUCTED in a certain skill and therefore possesses that skill;

c. is PERSUADED to adopt an opinion about or attitude towards something;

d. is MOTIVATED to perform or not perform a certain action; and/or

e. experiences a certain EMOTION.

To determine if an instance of lexicographical communication has been successful, the lexicographer needs to establish if $\mathrm{SQ}_{u}$ has been answered. This can only be done if the effect of the particular instance of lexicographical communication can be observed. The types of aim. $E_{l}$ identified in (47) should therefore be expanded to include a component that refers to an observable effect, since being informed/instructed/persuaded/motivated or experiencing a certain emotion is in itself not automatically observable. The value of this additional component will be particular to each type of LU. Assigning intentional effects to the $\mathrm{LM}_{l}\{\mathrm{n}\}$ of $\mathrm{LU}_{9}$ in (41) will result in the following analysis in terms of the TLC (focusing on the communicative user situation):

$$
\begin{aligned}
& \mathrm{LU}_{9 \backslash \mathrm{LU7}}=\text { item giving the definite article: "das" } \\
& \text { ref. } L_{1}-1\left[L_{9 \backslash L U 7}\right]=\text { Lexical item Buch takes the definite article } \\
& \text { das in the nominative case. } \\
& \rightarrow\left(\text { ref. } \mathrm{E}_{l}-1 » \text { ref. } \mathrm{LM}_{l}-1\left[\mathrm{LU}_{9 \backslash \mathrm{LU}}\right]\right)=\varnothing \\
& \exp . \mathrm{LM}_{l}-1 . . \mathrm{n}\left[\mathrm{LU}_{9 \backslash \mathrm{LU} 7}\right] \in \exp . \mathrm{SPS}\{\mathrm{n}\} \\
& \rightarrow\left(\exp . \mathrm{E}_{l}-1 \text { »exp. } \mathrm{LM}_{l}-1 . . \mathrm{n}\left[\mathrm{LU}_{9 \backslash \mathrm{LU}}\right]\right)=\varnothing \\
& \text { rel.LM }{ }_{l}-1 . . n\left[\mathrm{LU}_{9 \backslash \mathrm{LU7}}\right] \in \text { rel.SPS }\{\mathrm{n}\} \\
& \rightarrow\left(\text { rel.E } E_{l}-1 » r \text { rel.LM }{ }_{l}-1 . . n\left[\mathrm{LU}_{9 \backslash \mathrm{LU7}}\right]\right)=\varnothing \\
& \operatorname{aim} . \mathrm{LM}_{l}-1\left[\mathrm{LU}_{9 \backslash \mathrm{LU7}}\right]=\boldsymbol{r}\left(\text { ref.LM } \mathrm{LM}_{l}-1\left[\mathrm{LU}_{9 \backslash \mathrm{LU7}}\right]\right) \\
& \rightarrow\left(\text { aim. } E_{l}-1 » \text { aim. } \text { LM }_{l}-1\left[\mathrm{LU}_{9 \backslash \mathrm{LU}}\right]\right)=\text { INFORM: }[u \text { COM- } \\
& \text { BINES: the definite article das \& lexical item Buch in the } \\
& \text { nominative case.] } \in \text { tp. } s_{u} \\
& \rightarrow\left(\text { aim. } E_{l}-2 » \text { aim. } \text { LM }_{l}-1\left[\mathrm{LU}_{9 \backslash \mathrm{LU} 7}\right]\right)=\text { INFORM: }(u \text { APPLIES: } \\
& \text { the appropriate declension of the definite article das with } \\
& \text { lexical item Buch in the dative, accusative and genitive } \\
& \text { cases respectively) } \in \text { tp.s } s_{u} \\
& \rightarrow\left(\text { aim. } E_{l}-3 » \operatorname{aim}_{1} \text { LM }_{l}-1\left[\mathrm{LU}_{9 \backslash \text { LU7 }}\right]\right)=\text { PERSUADE: }(u \text { EVALU }- \\
& \text { ATES: the combination of the definite article das with } \\
& \text { lexical item Buch in the nominative case }=\text { correct }) \in \\
& \text { tr.s } s_{u} \\
& \rightarrow\left(\text { aim. } E_{l}-4 » \text { aim. } \text { LM }_{l}-1\left[\mathrm{LU}_{9 \backslash \mathrm{LUT}}\right]\right)=\text { PERSUADE: }(u \text { EVALU- } \\
& \text { ATES: the combination of a definite article } \neg \text { das with } \\
& \text { lexical item Buch in the nominative case }=\neg \text { correct) } \in \\
& \text { tr.s } \text { s }_{u} \\
& \rightarrow\left(\text { aim. } E_{l}-5 » \text { aim.LM }{ }_{l}-1\left[\mathrm{LU}_{9 \backslash \text { LUT }}\right]\right)=\text { PERSUADE: }(u \text { EVALU- }
\end{aligned}
$$


accusative and genitive cases respectively $=$ correct) $\in$ tr.s.

$\rightarrow\left(\right.$ aim. $E_{l}-6 »$ aim. $\left.\mathrm{LM}_{l}-1\left[\mathrm{LU}_{9 \backslash \mathrm{LU}}\right]\right)=$ PERSUADE: $(u$ EVALUATES: the application of $\neg$ (the appropriate declension of definite article das) with lexical item Buch in the dative, accusative and genitive cases respectively $=\neg$ correct) $\in \operatorname{tr}_{\mathrm{u}} \mathrm{s}_{u}$

aim. $\mathrm{LM}_{l}-2\left[\mathrm{LU}_{9 \backslash \mathrm{LU7}}\right]=\mathbf{r}$ (The word class of lexical item Buch is noun.)

$\rightarrow$ (aim. $E_{l}-1 »$ aim. $\left.\mathrm{LM}_{l}-2\left[\mathrm{LU}_{9 \backslash \mathrm{LU} 7}\right]\right)=$ INFORM: $(u$ APPLIES: lexical item Buch = the core of a noun phrase.) $\in$ tp. $s_{u}$ $\rightarrow\left(\right.$ aim. $E_{l}-2 »$ aim.LM $\left.M_{l}-2\left[L_{9 \backslash \text { LU7 }}\right]\right)=$ PERSUADE: $(u$ EVALUATES: the application (lexical item Buch $=$ the core of a noun phrase $)=$ correct $) \in$ tr.s $s_{u}$

$\rightarrow\left(\right.$ aim.E $E_{l}-3 »$ aim. LM $_{l}-2\left[\mathrm{LU}_{\left.9 \backslash \mathrm{LU}_{7}\right]}\right)=$ PERSUADE: $(u$ EVALUATES: the application (lexical item Buch $=\neg$ (the core of a noun phrase) $)=\neg$ correct $) \in$ tr.s $_{\mathcal{u}}$

aim. $\mathrm{LM}_{l}-3\left[\mathrm{LU}_{9 \backslash \mathrm{LU7}}\right]=\mathbf{r}($ The gender of lexical item Buch is neuter.)

$\rightarrow\left(\operatorname{aim} . \mathrm{E}_{l}\{\mathrm{n}\} » \operatorname{aim} . \mathrm{LM}_{l}-3\left[\mathrm{LU}_{9 \backslash \mathrm{LU} 7}\right]\right)=\left(\operatorname{aim} . \mathrm{E}_{l}\{\mathrm{n}\} » \operatorname{aim}\right.$. $\left.\mathrm{LM}_{l}-1\left[\mathrm{LU}_{9 \backslash \mathrm{LU}}\right]\right)$

("ᄀ" indicates negation.)

$\left\langle\text { aim. } \mathrm{E}_{l}-1 » \text { aim. } \mathrm{LM}_{l}-1\left[\mathrm{LU}_{9 \backslash \mathrm{LU}}\right]\right\rangle^{20}$ above could be described as follows in natural language:

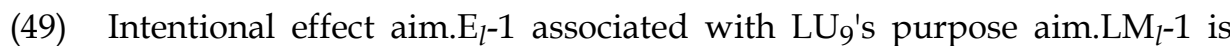
that the target user in the text production user situation $\left(=t_{p} . s_{u}\right)$ is INFORMED that the lexical item Buch takes the definite article das in the nominative case; therefore the target user COMBINES the definite article das with lexical item Buch in the nominative case.

In comparison $\left\langle\right.$ aim. $E_{l}-3 »$ aim. $\left.\mathrm{LM}_{l}-1\left[\mathrm{LU}_{9 \backslash \mathrm{LU7}}\right]\right\rangle$ could be described as follows:

(50) Intentional effect aim. $E_{l}-3$ associated with LUg's purpose aim.LM $_{l}-1$ is that the target user in the text reception user situation $\left(=t p . s_{u}\right)$ is PERSUADED that the lexical item Buch takes the definite article das in the nominative case; therefore the target user EVALUATES as correct the combination of the definite article das with lexical item Buch in the nominative case.

(49) and (50) constitute two of the observable intentional effects of aim.LM $\mathrm{LM}_{l}-1$ $\left[\mathrm{LU}_{9 \backslash \mathrm{LU7}}\right]$ that are diagnostic of successful lexicographical communication in the particular user situation. The key terms like combine and evaluate that form 
part of the aim. $E_{l}$ propositions relate directly to the observability and measurability of aim. El . They can be taken from education theory, for instance Bloom's revised taxonomy of educational objectives (cf. Anderson and Krathwohl 2001). ${ }^{21}$

It is now theoretically necessary to be able to express in a single statement the relation between a particular $\mathrm{LU}_{\mathrm{x}}$, a particular aim. $\mathrm{LM}_{l-y}$ of $\mathrm{LU}_{\mathrm{x}}$ and the aim. $E_{l}-z$ that follows from that $L U$ as associated with aim. $\mathrm{LM}_{l}-y$. Such a statement represents the lexicographic function $(=f)$ of $\mathrm{LU}_{\mathrm{x}}$ and can be formalised as follows: 22

$$
f\left[\mathrm{LU}_{\mathrm{x}}\right]=\left(\operatorname{aim} \cdot \mathrm{LM}_{l}-y\left[\mathrm{LU}_{\mathrm{x}}\right] \rightarrow\left(\mathrm{E}_{l}-z » \operatorname{aim} \cdot \mathrm{LM}_{l}-y\left[\mathrm{LU}_{\mathrm{x}}\right]\right)\right)
$$

The function of $\mathrm{LU}_{9}$ in (51) with regard to $\left\langle\right.$ aim. $E_{l}-1 »$ aim. $\left.\mathrm{LM}_{l}-1\left[\mathrm{LU}_{9 \backslash \mathrm{LU}}\right]\right\rangle$ can be expressed in natural language as follows:

(52) The first function of the item giving the definite article das of the lemma Buch is to STATE that the lexical item Buch takes the definite article das in the nominative case so that the target user in the text production user situation is INFORMED that the lexical item Buch takes the definite article das in the nominative case; therefore, the target user COMBINES the definite article das with the lexical item Buch in the nominative case.

This particular function $(=f-x)$ can be formalised as follows:

$$
f-1\left[\mathrm{LU}_{9 \backslash \mathrm{LU7}}\right]=\left(\operatorname{aim} \cdot \mathrm{LM}_{l}-1\left[\mathrm{LU}_{9 \backslash \mathrm{LU7}}\right] \rightarrow\left(\operatorname{aim} \cdot \mathrm{E}_{l}-1 » \operatorname{aim}_{\mathrm{L}} \mathrm{LM}_{l}-1\left[\mathrm{LU}_{9 \backslash \mathrm{LU7}}\right]\right)\right)
$$

The various classification possibilities of functions will not be dealt with here.

For each LU a set of functions $(=f\{\mathrm{n}\})$ can be formulated. Actual appeal user effects (aim. $E_{u}-1 . . n$ ) that result from a particular LU can then be compared against the sets of intended appeal effects (aim. $\mathrm{E}_{l}\{\mathrm{n}\}$ ) that constitute elements of the set of functions of the LU to determine whether lexicographical communication has been successful. The result of such a comparison will lead to the diagnosis of a particular aim. $\mathrm{E}_{\mathcal{U}^{-}} x$ as intentional or unintentional.

Consequently, an intentional actual appeal user effect can be referred to as a functional appeal effect $\left(f\right.$.aim. $\left.E_{u}-y\right)$, which occurs when the actual appeal user effect following from a particular LU is an element of the set of intentional appeal effects of that LU (as an element of the set of functions of that LU):

(54) If $\mathrm{LU}_{\mathrm{x}} \rightarrow$ aim. $\mathrm{E}_{\mathcal{u}^{-}-y}$

and aim. $\mathrm{E}_{u^{-}} y \in\left(\operatorname{aim} \cdot \mathrm{E}_{l}\{\mathrm{n}\}\left[\mathrm{LU}_{\mathrm{x}}\right] \in f\{\mathrm{n}\}\left[\mathrm{LU}_{\mathrm{x}}\right]\right)$

$\rightarrow$ aim. $\mathrm{E}_{u^{-}-y}=$ f.aim. $\mathrm{E}_{u^{-}} y$

$\therefore \mathrm{LU}_{\mathrm{x}} \rightarrow$ f.aim. $\mathrm{E}_{u^{-}} \mathrm{y}$

Unintentional actual user effects can be classified into two categories, i.e. nonfunctional effects and dysfunctional effects.

If actual effect aim. $E_{u}-y$ follows from $L_{\mathrm{x}}$ and is not an element of the set 
of intended effects aim. $E_{l}\{n\}$ of $L_{x}$ (as an element of the set of functions of $\left.L_{x}\right)$, then actual effect aim. $E_{u}-y$ is a non-functional effect $\theta$.aim. $E_{u^{-}}-y$ that follows from $\mathrm{LU}_{\mathrm{x}}$ :

$$
\begin{aligned}
& \text { If } \mathrm{LU}_{\mathrm{x}} \rightarrow \operatorname{aim} \cdot \mathrm{E}_{u^{-}} y \\
& \text { and aim. } \mathrm{E}_{u^{-}-y} \notin\left(\operatorname{aim} . \mathrm{E}_{l}\{\mathrm{n}\}\left[\mathrm{LU}_{\mathrm{x}}\right] \in f\{\mathrm{n}\}\left[\mathrm{LU}_{\mathrm{x}}\right]\right) \\
& \rightarrow \operatorname{aim} . \mathrm{E}_{u^{-}}-y=\theta \cdot \operatorname{aim} \cdot \mathrm{E}_{u^{-}} y \\
& \therefore \mathrm{LU}_{\mathrm{x}} \rightarrow \theta \text { aim. } \mathrm{E}_{u^{-}} y
\end{aligned}
$$

If actual effect aim. $E_{u}-y$ follows from $\mathrm{LU}_{\mathrm{x}}$ and negates an intended effect that is an element of the set of intended effects aim. $E_{l}\{n\}$ of $L U_{x}$ (as an element of the set of functions of $L_{x}$ ), then actual effect aim. $E_{u}-y$ is a dysfunctional effect $\Psi$ aim. $\mathrm{E}_{u}-y$ that follows from $\mathrm{LU}_{\mathrm{x}}$ :

$$
\begin{aligned}
& \text { If } \mathrm{LU}_{\mathrm{x}} \rightarrow \text { aim. } \mathrm{E}_{u^{-}}-\mathrm{y} \\
& \text { and aim. } \mathrm{E}_{u^{-}} y \rightarrow \neg\left(\operatorname{aim} . \mathrm{E}_{l}-z \in\left(\operatorname{aim} . \mathrm{E}_{l}\{\mathrm{n}\}\left[\mathrm{LU}_{\mathrm{x}}\right] \in f\{\mathrm{n}\}\left[\mathrm{LU}_{\mathrm{x}}\right]\right)\right) \\
& \rightarrow \text { aim. } \mathrm{E}_{u^{-}}-y=\Psi \text {.aim. } \mathrm{E}_{u^{-}}-y \\
& \therefore \mathrm{LU}_{\mathrm{x}} \rightarrow \Psi \text {.aim. } \mathrm{E}_{u^{-}}-\mathrm{y}
\end{aligned}
$$

Functional effects signal successful lexicographical communication and dysfunctional effects signal failed lexicographical communication. Non-functional effects are effects that were not foreseen within the framework of the functions of the relevant LUs, but that have not necessarily had an adverse effect on lexicographical communication. An example of a non-functional effect would be when a user uses a bilingual dictionary to find the meaning of a lexical item by deriving it from the translation equivalent provided (Beyer 2013). The function of the relevant translation equivalent is not to state the meaning of the lemma so that the user would be informed of its meaning to apply it in the user situation, but rather to state a translation equivalent so that the user would be informed of the translation equivalent and apply it in translating a text in the appropriate user situation. Although the user performed a successful dictionary consultation procedure and $\mathrm{SQ}_{u}$ was answered, it was not the "intention" of the lexicographer that this be the case; hence a non-functional effect occurred, even though the dictionary was useful to the user. ${ }^{23}$

A non-functional effect could also turn out to be an effect that could be regarded as functional, but it was not predicted in formulating the particular set of functions. Such an effect could then be incorporated into that set of functions, changing its status from non-functional to functional.

To revisit ref. $\mathrm{E}_{u}$, exp. $\mathrm{E}_{u}$ and rel. $\mathrm{E}_{u}$ in terms of the paradigm of functionality, the following propositions apply:

$$
\begin{aligned}
\text { a. } & \text { If } \mathrm{LU}_{\mathrm{x}} \rightarrow \text { ref. } \mathrm{E}_{u^{-}-y} \\
& \text { and ref. } \mathrm{E}_{u^{-}-y}=\varnothing \\
& \rightarrow \text { ref. } \mathrm{E}_{u^{-}-y}=f . \text { ref. } \mathrm{E}_{u^{-}} y \\
\therefore & \mathrm{LU}_{\mathrm{x}} \rightarrow f \text {.ref. } \mathrm{E}_{u^{-}} y
\end{aligned}
$$


b. If $\mathrm{LU}_{\mathrm{x}} \rightarrow$ exp. $\mathrm{E}_{u^{-}-y}$ and exp. $\mathrm{E}_{u}-y=\varnothing$

$\rightarrow \exp . \mathrm{E}_{u^{-}}-y=f . \exp . \mathrm{E}_{u^{-}} y$

$\therefore \mathrm{LU}_{\mathrm{x}} \rightarrow f$.exp. $\mathrm{E}_{u^{-}}-y$

c. If $\mathrm{LU}_{\mathrm{x}} \rightarrow$ rel. $\mathrm{E}_{u}-\mathrm{y}$

and rel. $\mathrm{E}_{u}-y=\varnothing$

$\rightarrow$ rel. $\mathrm{E}_{u}-y=f . r e l . \mathrm{E}_{u}-y$

$\therefore \mathrm{LU}_{\mathrm{x}} \rightarrow$ f.rel. $\mathrm{E}_{u}-\mathrm{y}$

When an unintentional (observable) effect occurs in any of these cases, that effect has to be analysed to arrive at the specific $\mathrm{LM}_{u^{-}-x}$ (and LU) from which the effect had followed. It can then be determined if the effect is non-functional or dysfunctional by measuring its value against the equivalent $\mathrm{LM}_{l}-x$ and the relevant $\mathrm{Xpt}_{u}\{\mathrm{n}\}$.

$$
\begin{aligned}
& \text { a. If ref. } E_{u} \neq \varnothing \\
& \text { ref. } E_{u}=\theta . \text { ref. } E_{u} \vee \Psi \text {.ref. } E_{u}
\end{aligned}
$$

b. If $\exp \cdot \mathrm{E}_{u} \neq \varnothing$

$\exp \cdot \mathrm{E}_{u}=\theta \cdot \exp \cdot \mathrm{E}_{u} \vee \Psi \cdot \exp \cdot \mathrm{E}_{u}$

c. If rel. $\mathrm{E}_{u} \neq \varnothing$

rel. $\mathrm{E}_{u}=\theta \cdot$ rel. $\mathrm{E}_{u} \vee \Psi \cdot$ rel. $\mathrm{E}_{u}$

(" $x \vee y$ " reads " $x$ or $y "$.

\section{The case of the vuvuzela}

In this section the TLC will be applied to the research problem as a framework to analyse the criticism levelled at the example sentence Vuvuzelas maak ' $n$ groot lawaai by sokkerwedstryde [ \pm Vuvuzelas make a lot of noise at soccer matches] presented during the keynote address mentioned in the introduction, and to determine why the criticism did not seem to be validated or dealt with constructively. First, a partial formal TLC analysis of the example sentence will be provided, followed by a description of the criticism against the background of the prevailing context.

\subsection{A formal TLC analysis of the relevant LU}

The following partial formal analysis of the example sentence is presented in as far as the various LMs are assumed to be true, since the author of this article is not involved with the dictionary project in question. 
(59) $\mathrm{LU}_{10}=$ example sentence: "Vuvuzelas maak 'n groot lawaai by sokkerwedstryde"

ref. $\mathrm{LM}_{l}-1\left[\mathrm{LU}_{10}\right]=$ Vuvuzelas make a lot of noise at soccer matches.

$\rightarrow\left(\right.$ ref.E $E_{l}-1 »$ ref.LM $\left.{ }_{l}-1\left[\mathrm{LU}_{10}\right]\right)=\varnothing$

exp. $\mathrm{LM}_{l}-1\left[\mathrm{LU}_{10}\right]=l$ is an expert in the treated languages.

$\rightarrow\left(\exp . \mathrm{E}_{l}-1 » \exp . \mathrm{LM}_{l}-1\left[\mathrm{LU}_{10}\right]\right)=\varnothing$

$\exp . \mathrm{LM}_{l}-2\left[\mathrm{LU}_{10}\right]=l$ is objective.

$\rightarrow\left(\exp . \mathrm{E}_{l}-1\right.$ »exp. $\left.\mathrm{LM}_{l}-2\left[\mathrm{LU}_{10}\right]\right)=\varnothing$

$\exp \cdot \mathrm{LM}_{l}-3\left[\mathrm{LU}_{10}\right]=l$ has zero bias.

$\rightarrow\left(\exp . \mathrm{E}_{l}-1 » \exp . \mathrm{LM}_{l}-3\left[\mathrm{LU}_{10}\right]\right)=\varnothing$

exp. $\mathrm{LM}_{l}-4\left[\mathrm{LU}_{10}\right]=l$ believes $\mathrm{LU}_{10}$ to be true.

$\rightarrow\left(\exp . \mathrm{E}_{l}-1 » \exp . \mathrm{LM}_{l}-4\left[\mathrm{LU}_{10}\right]\right)=\varnothing$

rel. $\mathrm{LM}_{l}-1\left[\mathrm{LU}_{10}\right]=u$ is a learner of either of the treated languages.

$\rightarrow\left(\right.$ rel. $E_{l}-1 »$ rel. $\left.\mathrm{LM}_{l}-1\left[\mathrm{LU}_{10}\right]\right)=\varnothing$

rel.:LM ${ }^{-}-2\left[\mathrm{LU}_{10}\right]=u$ possesses the set of language skills $\mathrm{LS}_{u}\{\mathrm{n}\}$ in either of the treated languages.

$\rightarrow\left(\right.$ rel. $\mathrm{E}_{l}-1 »$ rel. $\left.\mathrm{LM}_{l}-2\left[\mathrm{LU}_{10}\right]\right)=\varnothing$

rel. $\mathrm{LM}_{l}-3\left[\mathrm{LU}_{10}\right]=u$ possesses the set of dictionary usage skills $\mathrm{DS}_{u}\{\mathrm{n}\}$.

$\rightarrow\left(\right.$ rel.E $\left.{ }_{l}-1 » r e l . L_{l}-3\left[\mathrm{LU}_{10}\right]\right)=\varnothing$

aim.LMl $-1\left[\mathrm{LU}_{10}\right]=\boldsymbol{r}($ ref.LMl-1[LU 10$\left.]\right)$

$\rightarrow($ aim.El-1»aim.LMl-1[LU 10$])=$ INFORM: $\left(u\right.$ WRITES: LU $_{10}$. $)$

$\in \operatorname{tp} . \mathrm{s}_{\mathcal{u}}$

$\rightarrow$ (aim.E $l-2 »$ aim.LM $\left.l-1\left[L_{10}\right]\right)=\operatorname{PERSUADE}:(u$ EVALUATES:

$\mathrm{LU}_{10}=$ grammatically correct/possible.) $\in$ tr.s $u$

aim. $\mathrm{LM}_{l}-2\left[\mathrm{LU}_{10}\right]=\boldsymbol{r}$ (The lexical item vuvuzela can fulfil the role of subject/agent in an Afrikaans sentence.)

$\rightarrow$ (aim.E $l-1 »$ aim.LM $\left.l-2\left[L_{10}\right]\right)=$ PERSUADE: $(u$ WRITES: an Afrikaans sentence $\left(\neq \mathrm{LU}_{10}\right)$ with the lexical item vuvuzela in the role of subject/agent.) $\in$ tp.s $s_{u}$

$\rightarrow\left(\right.$ aim.El-2»aim.LMl-2[LU $\left.\left.{ }_{10}\right]\right)=\operatorname{PERSUADE}:(u$ EVALUATES: an Afrikaans sentence $\left(\neq \mathrm{LU}_{10}\right)$ with the lexical item vuvuzela in the role of subject/agent = grammatically correct) $\in$ tr.s $\mathcal{U}_{\mathcal{U}}$

aim. $\mathrm{LM}_{l}-3\left[\mathrm{LU}_{10}\right]=\mathbf{r}($ The lexical item vuvuzela combines frequently with the verb maak.)

$\rightarrow$ (aim.E $l-1 »$ aim.LM $\left.{ }^{-}-3\left[\mathrm{LU}_{10}\right]\right)=$ PERSUADE: $(u$ WRITES: an Afrikaans sentence $\left(\neq \mathrm{LU}_{10}\right)$ in which the lexical item vuvuzela combines with the verb maak.) $\in$ tp.s $u$

$\rightarrow\left(\right.$ aim.El-2»aim.LMl-3[LU $\left.\left.{ }_{10}\right]\right)=$ PERSUADE: $(u$ EVALUATES: an Afrikaans sentence $\left(\neq \mathrm{LU}_{10}\right)$ in which the lexical item vuvuzela combines with the verb maak = grammatically correct.) $\in$ tr.s $\mathcal{U}$ 
According to this partial analysis $\mathrm{LU}_{10}$ has at least 14 lexicographic functions, of which six are appeal or primary functions. The remaining eight may generally be regarded as default functions following from the dictionary's (assumed) ref.SPS $\{n\}, \operatorname{exp.SPS}\{n\}$ and rel.SPS $\{\mathrm{n}\}$.

\subsection{An informal representation of the actual effects}

The criticism of the example sentence can be paraphrased as follows:

(60) a. The delegate (as a potential user) expressed disappointment at the fact that he could not observe the notion of festivity and celebration, with which the vuvuzela is also associated, in the example. It seemed regrettable to him that the vuvuzela is associated only with excessive noise in the dictionary article.

b. The word noise in the example sentence, instead of, for instance sound, seems to portray the vuvuzela in a negative light as making a "sound, esp one that is loud and disturbing" (Collins English Dictionary), "a loud or unpleasant sound" (Macmillan).

\subsection{Context, frame of reference and user expectations}

The interpretation of the effects of lexicographical communication should take place against the background of the prevailing context. In the context-change theory of speech acts, context is defined as "a set of propositions, describing the beliefs, knowledge, commitments and so on of the participants in a discourse" (Levinson 1983: 276). In applying this definition to lexicographical communication, it follows that context $\mathrm{C}$ is the union of the sets of propositions describing $\mathrm{FoR}_{l}$ and $\mathrm{FoR}_{u}$ respectively:

$$
\mathrm{C}=\mathrm{FoR}_{l}\{\mathrm{n}\} \cup \mathrm{FoR}_{u}\{\mathrm{n}\}
$$

Context is anchored geographically, temporally and socially (i.e. culturally), since beliefs, knowledge, etc. vary geographically, temporally and socially. Ideally, $\operatorname{FoR}_{l}\{\mathrm{n}\}=\mathrm{FoR}_{u}\{\mathrm{n}\}$, but this is rarely the case in reality. Rather, lexicographical communication should strive towards the greatest possible intersection between $\operatorname{FoR}_{l}\{\mathrm{n}\}$ and $\mathrm{FoR}_{u}\{\mathrm{n}\}$ as informed by empirical research. This implies that there will be FoR elements that are not shared by the lexicographer and the target user, and that there might also be elements of $\mathrm{FoR}_{l}\{n\}$ that are not compatible with elements of $\mathrm{FoR}_{u}\{\mathrm{n}\}$. The following hypothetical FoR elements with regard to the vuvuzela as artefact are assigned to the lexicographer and the target user respectively for the purposes of this analysis: 24

(62) a. FoR For $_{l}-1=$ The vuvuzela is an instrument blown by fans at soccer matches. 
FoR ${ }_{l}-2=$ Many people complain about the loud sound made by vuvuzelas.

b. $\mathrm{FoR}_{u}-1=$ The vuvuzela is an instrument blown by fans at soccer matches.

FoR $_{u}-2=$ The vuvuzela is an icon of the 2010 Soccer World Cup tournament hosted by South Africa.

FoR $_{u^{-}} 3=$ The vuvuzela is an icon of the atmosphere of celebration and festivity that prevailed during the 2010 Soccer World Cup tournament in South Africa.

$\mathrm{FoR}_{u}-4=$ The vuvuzela represents the global recognition of South Africa and Africa in 2010.

FoR $_{u}-5=$ Many people complain about the loud sound made by vuvuzelas.

From the $\mathrm{FoR}_{u}\{\mathrm{n}\}$ might have followed $\mathrm{Xpt}_{u}\{\mathrm{n}\}$ :

(63) $\mathrm{FoR}_{u}\{\mathrm{n}\} \rightarrow \mathrm{Xpt}_{u}\{\mathrm{n}\}$

$$
\mathrm{Xpt}_{u}\{\mathrm{n}\}=\left\{\mathrm{Xpt}_{u}-1, \mathrm{Xpt}_{u}-2\right\}
$$

$\mathrm{Xpt}_{u}-1=\mathrm{A}$ South African dictionary treating the lexical item vuvuzela should refer to its iconic status. (»FoR $\left.\mathcal{u}^{-2}, 3\right)$

$\mathrm{Xpt}_{u}-2=\mathrm{A}$ South African dictionary treating the lexical item vuvuzela should mention South Africa. $\left(» \mathrm{FoR}_{u}-4\right)$

The intersection of $\operatorname{FoR}_{l}\{\mathrm{n}\}$ and $\mathrm{FoR}_{u}\{\mathrm{n}\}$ in (62) is limited to two elements:

(64) $\operatorname{FoR}_{l}\{\mathrm{n}\} \cap \mathrm{FoR}_{u}\{\mathrm{n}\}=\{$ (The vuvuzela is an instrument blown by fans at soccer matches.), (Many people complain about the loud sound made by vuvuzelas.)\}

(" $x \cap y$ " reads "the intersection of sets $x$ and $y "$.

\subsection{A formal analysis of the actual effects}

The actual user effects in (60) can be represented formally as follows:

(65) a. $\left(\mathrm{E}_{u}-1 \gg \mathrm{LU}_{10}\right)=\left(u\right.$ EVALUATES: $\mathrm{LU}_{10}=\neg$ accurate $)$

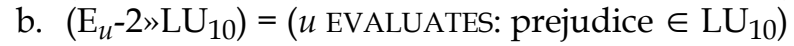

Each of the actual user effects can be analysed formally in (66) and (67) respectively (formalisation in part a and natural language equivalent in part $b$ ):

(66) a. $\left(\mathrm{E}_{u}-1 » \mathrm{LU}_{10}\right)=\left(u\right.$ EVALUATES: $\mathrm{LU}_{10}=\neg$ accurate $)$

$$
\begin{aligned}
& \therefore\left(\mathrm{E}_{\mathcal{u}^{-}}-1 » \mathrm{LU}_{10}\right)=\text { ref. } \mathrm{E}_{\mathcal{u}}-\mathrm{1}^{25} \\
& \text { ref. } \mathrm{E}_{u}-1 \neq \varnothing \\
& \therefore \text { ref. } E_{u^{-}}-1=\theta \text {.ref. } E_{u^{-}}-1 \vee \Psi \text {.ref. } E_{u^{-}}-1 \\
& \text { ref.LM }{ }_{u}-1<\text { ref.Xpt }_{u}\{\mathrm{n}\}
\end{aligned}
$$


ref.:LM ${ }^{-1}-1 \rightarrow$ ref. $E_{u^{-}}-1$

$\therefore$ ref. $E_{u}-1=\Psi$.ref. $E_{u}-1$

$\therefore\left(\mathrm{E}_{\mathcal{u}}-1 » \mathrm{LU}_{10}\right)=\left(\Psi . \mathrm{E}_{\mathcal{u}}-1 » \mathrm{LU}_{10}\right)$

b. Actual user effect $\left\langle E_{u}-1 » L U_{10}\right\rangle$ comprises of the user evaluating $L_{10}$ as inaccurate. Based on the evaluative expression inaccurate, $\left\langle\mathrm{E}_{u^{-}}\right.$ $\left.1 » \mathrm{LU}_{10}\right\rangle$ is a referential actual user effect ref. $E_{u}-1$. This effect is not a zero-effect; therefore it is an unintentional effect. Because ref. $\mathrm{LM}_{u}-1$ does not fulfil the set of referential user expectations $\operatorname{ref.Xpt}_{u}\{\mathrm{n}\}$, and ref. $E_{u}-1$ follows from ref. $\operatorname{LM}_{u}-1$, ref. $E_{u}-1$ is a dysfunctional effect. Therefore, $\left\langle\mathrm{E}_{\mathcal{u}}-1 » \mathrm{LU}_{10}\right\rangle$ is a dysfunctional effect.

a. $\left(\mathrm{E}_{u}-2 » \mathrm{LU}_{10}\right)=\left(u\right.$ EVALUATES: prejudice $\left.\in \mathrm{LU}_{10}\right)$

$\therefore\left(\mathrm{E}_{u}-2 » \mathrm{LU}_{10}\right)=\exp . \mathrm{E}_{u}-1$

exp. $\mathrm{E}_{u}-1 \neq \varnothing$

$\therefore$ exp. $\mathrm{E}_{u}-1=\theta \cdot \exp . \mathrm{E}_{u}-1 \vee \Psi \cdot \exp . \mathrm{E}_{u^{-}}-1$

$\exp . \mathrm{LM}_{u}-1=\neg \exp . \mathrm{LM}_{l}-3\left[\mathrm{LU}_{10}\right]$

exp.LM LM $_{u}-1 \rightarrow \exp . \mathrm{E}_{u}-1$

$\therefore$ exp. $\mathrm{E}_{u}-1=\Psi$.exp. $\mathrm{E}_{u}-1$

$\therefore\left(\mathrm{E}_{\mathcal{u}}-2 » \mathrm{LU}_{10}\right)=\left(\Psi \cdot \mathrm{E}_{\mathcal{u}}-2 » \mathrm{LU}_{10}\right)$

b. Actual user effect $\left\langle E_{u}-2 » L U_{10}\right\rangle$ comprises of the user evaluating $L U_{10}$ as containing prejudice. Based on the evaluative expression prejudice, $\left\langle\mathrm{E}_{u}-2 » \mathrm{LU}_{10}\right\rangle$ is an expressive actual user effect exp. $\mathrm{E}_{u}-1$. This effect is not a zero-effect; therefore it is an unintentional effect. Because exp. $\mathrm{LM}_{\mathcal{u}}-1$ negates exp. $\mathrm{LM}_{l}-3\left[\mathrm{LU}_{10}\right]$, and exp. $\mathrm{E}_{\mathcal{u}}-1$ follows from it, exp. $\mathrm{E}_{u}-1$ is a dysfunctional effect. Therefore, $\left\langle\mathrm{E}_{u}-2 » \mathrm{LU}_{10}\right\rangle$ is a dysfunctional effect.

The analyses show that both actual user effects are dysfunctional effects, i.e. effects not intended by the lexicographer, but effects that have threatened successful lexicographical communication.

\subsection{Why were the dysfunctional user effects not effectively neutralised?}

When dysfunctional effects occur, they should ideally be neutralised. Effective neutralisation requires the lexicographer to conduct a thorough analysis of a dysfunctional effect, like in (66) and (67) above, to arrive at the precise cause.

In the case of the vuvuzela, the TLC analysis (and the time) was not available to effectively neutralise the dysfunctional effects. The lexicographer's defence was mounted from a referential perspective which included arguments that the example sentence was not in any way incorrect and was representative of an appropriate corpus analysis, but at least one of the dysfunctional effects resulted from expressive information. Criticism and defence were therefore at least partially misaligned and possible unrecognised differences between the 
$\mathrm{FoR}_{l}$ and $\mathrm{FoR}_{u}$ hindered effective neutralisation further, since the $\mathrm{Xpt}_{u}\{\mathrm{n}\}$ was not known to the lexicographer.

\subsection{Conclusion}

It should be noted that the member of the conference audience who criticised the example sentence might not have been a member of the target user group, and that a typical target user might not have shared the delegate's FoR and $\mathrm{Xpt}_{u}\{\mathrm{n}\}$. It is therefore possible that the same dysfunctional effects might not have been observed with a target user.

As was stated in the introduction, however, the aim of this article is to present the TLC's capacity to scientifically address the case, and not to choose a side or to appoint a "winner". For this reason it is far less important that the

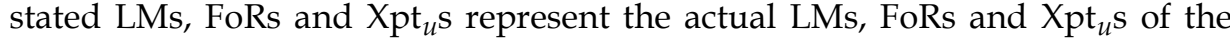
lexicographer and the delegate respectively than it is to demonstrate that the introduced theoretical framework facilitates scientific explanation. It would seem that exactly this has been demonstrated.

\section{Applying the TLC to dictionary evaluation}

The elements of the TLC introduced and applied in this article can be distilled to the following general questions that could guide formative and summative dictionary evaluation:

(68) a. Do the LMs and especially the aim.LMs support the purposes of the dictionary?

b. Are the ref.LMs correct, accurate, true, etc.?

c. Do the exp.LMs express the appropriate and desired attitudes, norms and values of the lexicographer (and by extension that of society)?

d. Do the rel.LMs reflect the desired perceived relation between the lexicographer and the target user?

\section{Perspective}

This article represents the first introduction of the TLC as a possible alternative or at least a complement to existing lexicographical theories. Some elements of this developing theory have been applied tentatively and informally in previous publications as components of a so-called communicative metalexicography. The theoretical elements that are formally developed in this article are also successfully applied to a real lexicographical situation, which demonstrates its validity.

Currently, the TLC seems to be situated in the overlapping area between 
semiotics and linguistics, which supports the argument that lexicography is a highly interdisciplinary field of study.

This article in particular has drawn significantly on professional communication and what could be referred to as basic classical speech act theory. Work ahead includes the full exploration of speech act theory and conversational implicature for the further development of the TLC, but also other theories in pragmatics, as well as the disciplines of text linguistics and document design. Furthermore, establishing the level of abstraction to which the relations between the sets of propositions and qualities developed in the process could be generalised would be central in an eventual pursuit of a more general theory of lexicographical communication.

The TLC is in its infancy, and as such offers exciting research potential. Nevertheless, this article has already demonstrated that this theory possesses explanatory power, and that is one of the key requirements for a scientific theory.

\section{Notes}

1. This seems to be the English translation of a work that had originally appeared in Chinese in 1991.

2. Beyer (in preparation) takes due cognisance of this work. For the purposes of this article an elaboration is not relevant here.

3. The principle of expressibility has been criticised by some scholars (cf. Levinson 1983). However, addressing the criticism falls outside the scope of this article.

4. Wiegand (e.g. 1990: 13-14) would regard the linguistic symbol "n." in $\mathrm{LU}_{3}$ as an instance of the textual condensation of the linguistic symbols (i.e. the sentence) "The lexical item book is a noun" in $\mathrm{LM}_{l}$, since $\mathrm{LM}_{l}$ is a full-sentence representation of $\mathrm{LU}_{3}$. In the TLC, however, textual condensation is not recognised to the full extent that Wiegand describes it. In as far as "n." is an abbreviation of "noun", textual condensation does apply. However, a symbol like the tilde " ", traditionally used to represent the lemma sign, is not characterised as an instance of the textual condensation of the lemma sign, but rather as an instance of lexicographical anaphora (which can, like textual condensation, be employed to save space in a printed dictionary). The encoding of $\mathrm{LM}_{l}$ in $\mathrm{LU}_{3}$ is preceded by an instance of what could be referred to as pre-encoding textual condensation: the symbol "noun" is textually condensed to the symbol "n." before the message "The lexical item book is a noun" is encoded in the symbol "n." to create $\mathrm{LU}_{3}$. The encoding process is therefore not an instance of textual condensation (or of lexicographical anaphora). Rather, it becomes apparent that, apart from the code system (i.e. the language) that is described by means of lexicographical communication, the dictionary employs its own code system consisting of its own types of signs and symbols (e.g. "n." instead of "The lexical item book is a noun.") organised according to its own code (i.e. not exclusively the grammar of the language that is the subject of the dictionary, but also the "dictionary grammar" that is realised in the various lexicographical structures). In this way the TLC reveals that the dictionary user, in attempting to gain command of one code system (i.e. the treated language) by consulting the dictionary, first needs to sufficiently command the mediating hybrid code system (i.e. the lexicographical symbols and structures in conjunction with the relevant linguistic symbols and structures) that is employed in the 
dictionary. This revelation could inform approaches to user guide design and dictionary pedagogies (that could, for example, be represented by slogans such as "Do you speak Lexicographish?"). This insight also facilitates the description of the problem with many user guides and dictionary pedagogies as comparable to a teacher starting the first lesson in English as a Foreign Language with the statement: $\mathrm{S} \rightarrow \mathrm{NP}$ VP.

5. There are additional differences in the denotations of the terms data and information as used by the respective theories and information as used by the TLC, but elaboration on them falls outside the scope of this article.

6. Various types of LU can therefore be distinguished, e.g. along the lines of data categories in the function theory or indicator types in the text theory, but the presentation of such a classification falls outside the scope of this article.

7. For generative (i.e. dictionary-making) purposes the order can simply be reversed.

8. Even in the purest informative referential text, such as a telephone directory, an identity of the sender is encoded, even if it is an identity by default. Consider, however, a telephone directory containing numerous glaring errors with regard to telephone numbers or the alphabetical ordering of surnames and company names. Obviously these are referential and access issues, but the nature and extent of the errors can convey expressive information to the user that can be constructed in the expressive message (representing the image): The publisher is incompetent.

9. The marketing of dictionaries is also a valid research subject in the TLC; in this case the cognate discipline of marketing communication is especially informative (as distinguished from the discipline of interpersonal communication, which forms the communication theory basis for this article).

10. Many of the symbols (words) in which these characteristics are encoded are in themselves ambiguous, which poses a challenge to the TLC not unlike that faced by, for instance, componential analysis in structural semantics. The same argument applies to the (re)construction of information and messages encoded in and decoded from utterances, since messages are expressed in natural language. A possible solution lies in propositional calculus, but this option will not be explored here.

11. Currently this is a hypothesis that should be tested empirically.

12. $\mathrm{FoR}_{l}$ and $\mathrm{FoR}_{u}$ are indicated by the broken line boxes enclosing lexicographer and target user respectively in the lexicographical communication model in figure 1.

13. The public pages of the website do not contain any evidence of SPSs. To contribute to the dictionary, a contributor has to log in via his/her Facebook or Gmail account and agree to surrender irrelevant information from these accounts. The author was not prepared to take this step to ascertain whether SPSs exist in the members' area.

14. The statement of the hypotheses does not presuppose that they are or have been proven true.

15. By means of the so-called two-step flow theory from the discipline of mass communication (cf. e.g. Steinberg 2007), the TLC can account for the phenomenon that target users are sometimes represented in these types of situation by non-target users or secondary target users. (The exact extent to which the respondents in this case can be seen to represent the primary target user group is not relevant for the purposes of the discussion.)

16. The $\mathrm{p} . \mathrm{SQ}_{u}$ is formalised as an illocutionary act to align with the aim. $\mathrm{LM}_{l}$ that offers its answer. p.SQ $\mathrm{Q}_{\mathcal{u}}$ follow from "raw" potential user questions $\left(=\mathrm{p} \cdot \mathrm{Q}_{\mathcal{u}} \mathrm{s}\right)$. For example: 
p. $Q_{u^{-1}}=$ What is the part of speech of the lexical item Buch?

p. $Q_{\mathcal{u}^{-2}}=$ Is the lexical item Buch a noun?

p. $Q_{u^{-1,2}} \rightarrow$ p.SQ $Q_{u^{-1} \backslash G E D}$

p.SQ $Q_{u}-1 \backslash G E D=$ ?(The word class of lexical item Buch is ...)

Between $\mathrm{SQ}_{u}$ and aim. $\mathrm{LM}_{\mathcal{u}}$ in a communication sequence should be inserted user consultation objective $\mathrm{CO}_{u}$, thus: $\mathrm{p} . \mathrm{Q}_{u} \rightarrow \mathrm{p} . \mathrm{SQ}_{u} \rightarrow \mathrm{CO}_{u} \rightarrow$ aim. $\mathrm{LM}_{u}$. In the present case $\mathrm{CO}_{u}=$ "Find: aim. $\mathrm{LM}_{l}-2\left[\mathrm{LU}_{9 \backslash \mathrm{LU} 7]} \in G E D " . \mathrm{CO}_{u}\right.$ represents the user's intention to navigate the various structures of GED to find the needed information (LM) to answer $\mathrm{SQ}_{\mathcal{u}}$. For the purposes of this article $\mathrm{CO}_{\mathcal{U}}$ is irrelevant, as the successful navigation of GED's structures to arrive at the sought $\mathrm{LM}$ is assumed. $\mathrm{SQ}_{\mathcal{u}}$ s are also not discussed in detail.

17. In utilising the TLC for generative purposes, at least one aim. $\mathrm{LM}_{l}$ must answer every p.SQ $\mathrm{Q}_{u}$.

18. Cf. the general typology of lexicographical labels proposed in Beyer (2011).

19. Zero-effects are unlikely to occur in the typical face-to-face interpersonal communication situation, since a receiver's lack of response to a sender's message could in itself represent feedback and therefore an observable effect.

20. Pointed brackets are used to demarcate the limits of complex formal expressions in normal text.

21. This interdisciplinary application allows the TLC to accommodate formal assessment in dictionary pedagogies.

22. It should be noted here that the term (lexicographic) function has a distinctly different denotation and scope than the identical term in the function theory. What the function theory refers to as lexicographic function is accounted for (with adaptations) in the TLC by the term usage purpose (cf. Beyer 2013, in preparation). The function theory's concept of function is not discussed here; cf. Tarp (2008) for a detailed elaboration. The concept also bears limited resemblance to the concept of function in mathematics and set theory, although the same abbreviation is used.

23. The concept of the usefulness of a dictionary exists in the TLC (cf. Beyer 2013), but it is not pertinent to the present article.

24. These FoR elements are purely hypothetical and have not been confirmed with either party.

25. This conclusion is based on the fact that $\mathrm{LU}_{10}$ is evaluated as inaccurate. A specific set of evaluative expressions (such as accurate, complete, true) can be assigned to express evaluations of ref.LMs. Using such an expression when evaluating an LU indicates an evaluation of a ref.LM[LU]. Similarly, sets of evaluative expressions can be designated evaluative expressions for exp.LMs and rel.LMs respectively.

\section{Acknowledgement}

The author wishes to thank Prof. Ulrich Heid of the University of Hildesheim, Germany, for his constructive criticism on a draft manuscript of this article that has resulted in an improved product. His contribution is part of an on-going scientific collaboration between the University of Hildesheim and the University of Namibia in the framework of the SeLA project: Scientific e-Lexicography for Africa. Ultimately, however, the author remains solely responsible for the contents. 


\section{References}

\section{A. Primary literature (dictionary data)}

Macmillan = Macmillan Dictionary online <http://www.macmillandictionary.com/> [Accessed 18 August 2014]

Collins English Dictionary online <http://www.collinsdictionary.com/> [Accessed 18 August 2014]

Urban Dictionary <http://www.urbandictionary.com/> [Accessed 24 July 2014]

\section{B. Secondary literature}

Anderson, L.W. and D.R. Krathwohl (Eds.). 2001. A Taxonomy for Learning, Teaching, and Assessing: A Revision of Bloom's Taxonomy of Educational Objectives. London/New York: Longman.

Atkins, B.T.S. and M. Rundell. 2008. The Oxford Guide to Practical Lexicography. Oxford: Oxford University Press.

Austin, J.L. 1962. How to Do Things with Words. Oxford: Clarendon Press.

Bergenholtz, H. 2003. User-oriented Understanding of Descriptive, Proscriptive and Prescriptive Lexicography. Lexikos 13: 65-80.

Beyer, H.L. In preparation. Lexicography as Communication. Unpublished manuscript.

Beyer, H.L. 2006. 'n Voorlopige model vir die sistematiese beskrywing van gebruikersvriendelikheid in woordeboeke. Lexikos 16: 46-66.

Beyer, H.L. 2009. 'n Teoretiese basis vir kontekstualisering in tweetalige woordeboeke. Lexikos 19: $1-22$.

Beyer, H.L. 2010. Kontekstuele bepalers by die beplanning van skoolwoordeboeke. Lexikos 20: 52 72.

Beyer, H.L. 2011. 'n Algemene tipologie van leksikografiese etikette. Journal of Humanities 51(3): 419-445.

Beyer, H.L. 2013. Glosse en vertaalkomplemente in tweetalige woordeboeke. Botha, W., P. Mavoungou and D. Nkomo. (Eds.). 2013. Festschrift RUFUS H. GOUWS: 20-38. Stellenbosch: SUN PReSS.

Bierwisch, M. 1980. Semantic Structure and Illocutionary Force. Searle, J.R., F. Kiefer and M. Bierwisch. (Eds.). 1980. Speech Act Theory and Pragmatics: 1-35. Dordrecht/Boston/London: D. Reidel.

Bogaards, P. 2010. Lexicography: Science without Theory? De Schryver, G.-M. (Ed.). 2010. A Way with Words: Recent Advances in Lexical Theory and Analysis. A Festschrift for Patrick Hanks: 313322. Kampala: Menha.

Brown, G. and G. Yule. 1983. Discourse Analysis. Cambridge: Cambridge University Press.

Carstens, W.A.M. and K. van de Poel. 2010. Teksredaksie. Stellenbosch: SUN PReSS.

Cleary, S. (Ed.). 2003. The Communication Handbook. Second edition. Lansdowne: Juta.

Cruse, A. 2011. Meaning in Language. An Introduction to Semantics and Pragmatics. Third edition. Oxford: Oxford University Press.

De Schryver, G.-M. 2012. Trends in Twenty-five Years of Academic Lexicography. International Journal of Lexicography 25(4): 464-506.

Fielding, M. and F. du Plooy-Cilliers. 2014. Effective Business Communication in Organisations. Preparing Messages that Communicate. Fourth edition. Cape Town: Juta. 
Fontenelle, T. 2011. Lexicography. Simpson, J. (Ed.). 2011. The Routledge Handbook of Applied Linguistics: 53-66. London/New York: Routledge.

Gouws, R.H. 2012. Who can Really be Called a Lexicographer? Lexikos 22: 217-225.

Grice, H.P. 1975. Logic and conversation. Cole, P. and J.L. Morgan (Eds.). 1975. Syntax and Semantics 3: Speech Acts: 41-58. New York: Academic Press.

Hartmann, R.R.K. 1989. Sociology of the Dictionary User: Hypotheses and Empirical Studies. Hausmann, F.J., O. Reichmann, H.E. Wiegand and L. Zgusta. (Eds.). 1989-1991. Wörterbücher. Ein internationales Handbuch zur Lexikographie/Dictionaries. An International Encyclopedia of Lexicography/Dictionnaires. Encyclopédie internationale de lexicographie: 102-111. Berlin/New York: Walter de Gruyter.

Janssen, D. (Ed.). 1996. Zakelijke communicatie I. Groningen: Wolters-Noordhoff.

Kempson, R.M. 1977. Semantic Theory. Cambridge: Cambridge University Press.

Kosch, I. 2013. Expectation Levels in Dictionary Consultation and Compilation. Lexikos 23: 201-208.

Levinson, S.C. 1983. Pragmatics. Cambridge: Cambridge University Press.

Louw, P.A. and H.L. Beyer. In preparation. The Lexicography of Afrikaans. Hanks, P. and G.-M. de Schryver. (Eds.). In preparation. International Handbook of Modern Lexis and Lexicography. Heidelberg: Springer-Verlag.

Lyons, J. 1977. Semantics. Volume 1. Cambridge: Cambridge University Press.

Moon, R. 2014. Meanings, Ideologies, and Learners' Dictionaries. Abel, A., C. Vettori and N. Ralli. (Eds.). 2014. Proceedings of the XVI EURALEX International Congress: The User in Focus, EURALEX 2014, Bolzano/Bozen, Italy, July 15-19, 2014: 85-105. Bolzano/Bozen: Institute for Specialised Communication and Multilingualism.

Piotrowski, T. 2009. Review of Lexicography in the Borderland between Knowledge and Non-Knowledge. General Lexicographical Theory with Particular Focus on Learner's Lexicography (Tarp 2008). International Journal of Lexicography 22(4): 480-486.

Ptaszyñski, M.O. 2009. Review of Bilingual Lexicography from a Communicative Perspective (Yong and Peng 2007). International Journal of Lexicography 22(2): 211-218.

Rundell, M. 2012. It Works in Practice but Will It Work in Theory? The Uneasy Relationship between Lexicography and Matters Theoretical. Fjeld, R.V. and J.M. Torjusen. (Eds.). 2012. Proceedings of the 15th EURALEX International Congress, 7-11 August 2012, Oslo: 47-92. Oslo: Department of Linguistics and Scandinavian Studies, University of Oslo.

Sebeok, T.A. 2006. Communication. Cobley, P. (Ed.). 2006. Communication Theories. Critical Concepts in Media and Cultural Studies. Volume 1: 43-56. London/New York: Routledge.

Searle, J.R. 1969. Speech Acts. An Essay in the Philosophy of Language. Cambridge: Cambridge University Press.

Steehouder, M. et al. 1999. Leren communiceren. Groningen/Houten: Noordhoff.

Steinberg, S. 2007. An Introduction to Communication Studies. Cape Town: Juta.

Tarp, S. 2008. Lexicography in the Borderland between Knowledge and Non-knowledge. General Lexicographical Theory with Particular Focus on Learner's Lexicography. Lexicographica Series Maior 134. Tübingen: Max Niemeyer.

Van Cuilenburg, J.J., O. Scholten and G.W. Noomen. 1992. Communicatiewetenschap. Second edition. Bussum: Dick Coutinho.

Van Sterkenburg, P. 2003. 'The' Dictionary: Definition and History. Van Sterkenburg, P. (Ed.). 2003. A Practical Guide to Lexicography. Terminology and Lexicography Research and Practice 6: 3-17. Amsterdam/Philadelphia: John Benjamins. 
http://lexikos.journals.ac.za

Wiegand, H.E. 1977. Nachdenken über Wörterbücher. Aktuelle Probleme. Drosdowski, G., H. Henne and H.E. Wiegand (Eds.). 1977. Nachdenken über Wörterbücher: 51-102. Mannheim/Vienna/ Zürich: Bibliographisches Institut.

Wiegand, H.E. 1990. Printed Dictionaries and Their Parts as Texts. An Overview of More Recent Research as an Introduction. Lexicographica. International Annual of Lexicography 6: 1-126.

Wiegand, H.E. 1996. A Theory of Lexicographic Texts: An Overview. South African Journal of Linguistics 14(4): 134-149.

Yong, H. and J. Peng. 2007. Bilingual Lexicography from a Communicative Perspective. Terminology and Lexicography Research and Practice 9. Amsterdam/Philadelphia: John Benjamins. 